\title{
PREVALENCE OF AND RISK FACTORS
}

FOR FELINE HYPERTHYROIDISM IN

\section{SOUTH AFRICA}

\author{
by
}

\section{Joanne L. McLean}

Submitted in partial fulfilment of the requirements for the degree of

\section{MMedVet (Med)}

Companion Animal Clinical Studies

Faculty of Veterinary Science

University of Pretoria

Pretoria, October 2016 


\title{
Dissertation
}

\section{Prevalence of and risk factors for feline}

\author{
hyperthyroidism in South Africa
}

\section{Joanne L. McLean}

Supervisor:

Prof. J.P. Schoeman

Co-supervisor:

Dr. R.G. Lobetti

Department:

Companion Animal Clinical Studies

Faculty of Veterinary Science

University:

University of Pretoria 


\section{Declaration}

I, Joanne Leslie McLean, do hereby declare that the research presented in this dissertation, was conceived and executed by myself, and apart from the normal guidance from my supervisor, I have received no assistance.

Neither the substance, nor any part of this dissertation has been submitted in the past, or is to be submitted for a degree at this university or any other university.

This dissertation is submitted in partial fulfilment of the requirements for the degree of MMedVet (Med) in Veterinary Science.

I hereby grant the University of Pretoria free license to reproduce this dissertation in part or as a whole, for the purpose of research or continuing education

Signed:

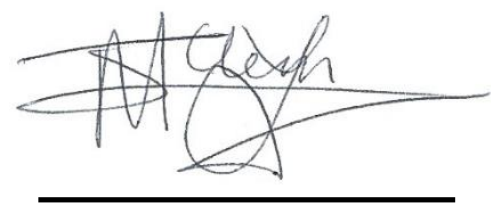

J.L. McLean

Date: $\quad \underline{02 / 10 / 2016}$ 


\section{Acknowledgments}

I would like to thank the following:

- Prof Johan Schoeman, my supervisor, for providing the idea for this project and the invaluable guidance on all aspects of the project as well as financial support for the research.

- Dr Remo Lobetti, my co-supervisor and mentor, for his invaluable guidance, endless support, encouragement and patience throughout the project.

- Prof Peter Thomson for patiently performing all the statistical analyses.

- To all the private veterinarians and veterinary nurses at the participating practices who found time amongst their busy schedules to collect the samples and complete the questionnaires.

- Ms. Nicol Schneider and all her staff at Idexx Laboratories, who not only took care of preparing and freezing the samples but also provided valuable support in transportation of the samples to the various laboratories.

- Mrs Carien Muller and the technicians in the Onderstepoort clinical pathology laboratory for performing the $\mathrm{tT}_{4}$ and $\mathrm{cTSH}$ analyses.

- Mrs Helen Evans from Nationwide Specialist Laboratories for kindly performing the $\mathrm{fT}_{4}$ analyses.

- Waltham Foundation, Waltham Centre for Pet Nutrition, Waltham-on-theWorlds, United Kingdom who generously provided financial support for the project.

- Lastly, but most importantly, my amazing husband, Ryan, who endured my endless frustrations but never wavered in his love, support and belief in me. 


\section{List of Contents}

Declaration

iii

Acknowledgements

iv

List of Contents

v

List of Tables

vii

Summary

viii

Chapter 1: Literature Review

1.1 Introduction 1

1.2 Worldwide Prevalence 1

1.3 Risk Factors 3

1.4 Clinical Signs 11

1.5 Diagnosis 12

$\begin{array}{ll}\text { Chapter 2: Objectives } & 16\end{array}$

2.1 Problem Statement 16

2.2 Research Questions 16

$\begin{array}{lll}2.3 & \text { Benefits } & 16\end{array}$

$\begin{array}{ll}\text { Chapter 3: Materials and Methods } & 19\end{array}$

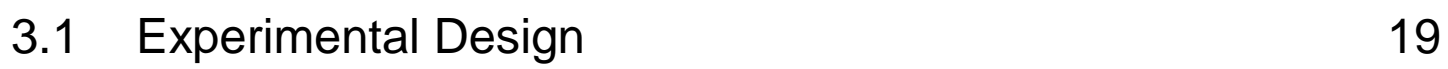

3.2 Experimental Procedures 19

$\begin{array}{lll}3.3 & \text { Observations } & 19\end{array}$

3.3.1 Laboratory Tests 19

3.3.2 Variables- Risk Factors 20 
4.1 Study Population 23

4.2 Laboratory Results for Study Population 23

4.3 Laboratory Results for Hyperthyroid Cats 24

4.4 Prevalence of Hyperthyroidism in Study Population 26

4.5 Risk Factors 26

4.5.1 Univariable Analysis 26

4.5.2 Multivariate Analysis $\quad 29$

4.6 Historical and Clinical Findings 29

4.6.1 Univariable Analysis $\quad 29$

Chapter 5: Discussion 32

Chapter 6: Conclusion 38

$\begin{array}{ll}\text { References } & 39\end{array}$

Addendum A: Questionnaire Part I 48

Addendum B: Questionnaire Part II 49

Addendum C: Cover Letter $\quad 50$

Addendum D: Research Publication Emanating from

this Study 


\section{List of Tables}

Table 1: Signalment and thyroid function in 21 hyperthyroid

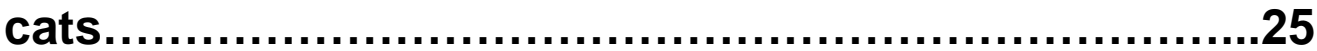

Table 2: Prevalence of hyperthyroidism in 302 cats.................26

Table 3: Univariable analysis of risk factors for feline hyperthyroidism.

Table 4: Final logistic regression model of risk factors for feline hyperthyroidism.................................................29

Table 5: Clinical features in 21 hyperthyroid cats .30

Table 6: Univariate analysis of clinical signs associated with feline hyperthyroidism 


\section{Summary}

Feline hyperthyroidism is a metabolic disease of middle-aged to older cats that has shown a marked increase in its world-wide prevalence within the last three decades. This disorder is now recognised as the most common feline endocrinopathy in many geographical locations, with diabetes mellitus coming a close second. Epidemiological studies performed to date have also suggested a geographic variation in the prevalence of the disease. This seemingly apparent variation may, in fact, reflect differences in dietary, environmental or genetic factors. Although clinical features of feline hyperthyroidism as well as its pathological lesions are well described, the exact pathogenesis of the disease still remains obscure and despite a plethora of epidemiological studies, clear risk factors for the disease have not been identified. Further information on worldwide prevalence of the disease and possible causative factors would increase our understanding of the aetiology of this disease and help identify any preventive measures.

As far as the author is aware, prevalence studies have not yet been performed in South Africa, a geographic area in which hyperthyroidism in cats has relatively recently been observed and reported and the incidence of which anecdotally appears to be on the increase. The purpose of this study was to determine the prevalence of feline hyperthyroidism in South Africa and to identify any potential risk factors associated with the disease in this geographic location.

This analytical cross-sectional study was conducted in cats that were presented for either geriatric check-ups and routine vaccinations or various illnesses at five general veterinary practices throughout South Africa between February 2014 and June 2015. Cats were included in the study if they were nine years of age or older and had resided solely in South Africa. Cats were excluded from the study if their demeanour precluded the collection of a blood sample, or if they had been treated with drugs that could potentially affect $\mathrm{tT}_{4}$ and $\mathrm{TSH}$ concentrations. At the time of blood sampling a questionnaire was completed regarding the health status of the cat, vaccination history, internal and external parasite control, diet and environment. Consent for blood 
collection was obtained from the owners and ethical approval for the study was also applied for and granted by the Animal Ethics Committee of the University of Pretoria.

Serum $\mathrm{tT}_{4}$ and $\mathrm{cTSH}$ concentrations were determined in all cats by use of a chemiluminescent competitive immunoassay (Immulite® 1000 Canine total T4, Siemens Medical Solutions Diagnostics) and a chemiluminescent immunometric assay (Immulite $\mathbb{B} 1000$ Canine TSH, Siemens Medical Solutions Diagnostics) respectively. The reference interval for $\mathrm{tT}_{4}$ was $14-50 \mathrm{nmol} / \mathrm{L}$ and for $\mathrm{CTSH} 0$ $0.07 \mathrm{ng} / \mathrm{ml}$ (laboratories historical reference intervals). Serum $\mathrm{fT}_{4}$ concentrations were measured in cats with a serum $\mathrm{tT}_{4}$ concentration between $30-50 \mathrm{nmol} / \mathrm{L}$ and a serum cTSH concentration less than $0.03 \mathrm{ng} / \mathrm{ml}$ using equilibrium dialysis (Antech Diagnostics Inc $^{\circledR}$ Free $\mathrm{T}_{4}$ by Equilibrium Dialysis) with a reference interval of 10 $50 \mathrm{pmol} / \mathrm{L}$ (laboratories historical reference intervals). All cats with a serum $\mathrm{tT}_{4}$ concentration greater than $50 \mathrm{nmol} / \mathrm{L}$ or cats with a serum $\mathrm{tT}_{4}$ concentration between 30-50 nmol/L, a serum cTSH concentration less than $0.03 \mathrm{ng} / \mathrm{ml}$ and a serum $\mathrm{fT}_{4}$ concentration greater than $50 \mathrm{pmol} / \mathrm{L}$ were classified as hyperthyroid.

Prevalence of hyperthyroidism, with exact binomial 95\% confidence intervals (Cls), was calculated for all cats combined, for cats classified as healthy (no clinically significant disease identified) and for those classified as sick. Prevalence was compared between healthy and sick cats using a two-tailed Fisher's exact test.

Univariable associations between potential risk factors and hyperthyroidism were assessed using a two-tailed Fisher's exact test. Thereafter, all predictors were entered into a multiple logistic regression model to estimate their effect on the risk of hyperthyroidism. Associations between clinical signs and hyperthyroidism were assessed on a univariable level using a two-tailed Fisher's exact test.

The study population consisted of a total of 302 cats. The most common breeds represented included domestic shorthair (DSH) $(n=201)$, domestic longhair (DLH) $(n=29)$, Siamese and Siamese crosses $(n=26)$, Persian and Persian crosses $(n=10)$, Burmese $(n=10)$, Balinese $(n=6)$ and Maine Coon and Maine Coon crosses $(n=5)$. There were 161 females and 141 males, 265 of which were sterilised. The median age of the cats was 12 years (range 9-24 years).

Twenty-one cats were diagnosed as being hyperthyroid. The prevalence of hyperthyroidism within the study population was $7 \%[95 \% \mathrm{Cl}: 4.4,10]$ with no 
significant difference in prevalence between healthy $(5.1 \%[1.9,11])$ and sick $(8.2 \%$ $[4.6,13])$ cats. Although the prevalence of hyperthyroidism within the female population of cats $(13 / 161$ cats $-8 \%)$ was higher than that in the male population of cats (8/141 cats- $6 \%)$, the difference was not statistically significant. Likewise, the proportion of non-purebred cats that were hyperthyroid (18/241 cats- $8 \%$ ) was higher than that of purebred cats $(3 / 61$ cats $5 \%)$. It was also found that the proportion of Siamese and Siamese cross cats with hyperthyroidism (1/26 cats-3.8\%) was lower compared to that of all other breeds (20/276 cats $-7.2 \%)$. The differences, however, were again not statistically significant. No statistically significant relationship between vaccinations, parasite control or indoor environment and hyperthyroidism was observed.

Only age and the presence of canned food in the diet were retained in the final logistic regression model of risk factors. Cats $\geq 12$ years of age $(\mathrm{OR}=4.3[95 \% \mathrm{Cl}: 1.2,15], \mathrm{p}=$ 0.02 ) and cats with canned food in their diet (OR=2.1 [95\% Cl: $0.8,5.4], \mathrm{p}=0.1$ ) were more likely to be diagnosed with hyperthyroidism.

Weight loss and vomiting were the most common findings, followed by tachypnoea, tachycardia, presence of a cardiac murmur and polyphagia. Clinical features typically associated with hyperthyroidism were only noted in 14 of the 21 hyperthyroid cats and only 2 had a palpable goitre. Univariable analysis for these clinical signs as predictors of hyperthyroidism demonstrated that hyperthyroid cats were more likely to present with weight loss $(\mathrm{OR}=3.2[95 \% \mathrm{Cl}: 1.2,8.9], \mathrm{p}=0.01)$ and with a heart rate $\geq 200 \mathrm{bpm}$ $(\mathrm{OR}=5[95 \% \mathrm{Cl}: 1.7,16.1], \mathrm{p}=0.01)$ than cats without the disease.

Feline hyperthyroidism appears to be a relatively common disease in older cats presenting to private veterinary clinics in South Africa. Hyperthyroidism needs to be considered in any older cat demonstrating weight loss or a heart rate $\geq 200$ in this cat population. The risk factors for development of feline hyperthyroidism identified in South Africa's relatively isolated population of cats appear to be somewhat similar to those that have been identified elsewhere. 


\section{Chapter 1}

\section{Literature Review}

\subsection{Introduction *}

Feline hyperthyroidism (thyrotoxicosis) is a multi-systemic disorder arising from excess production of the active thyroid hormones (triiodothyronine [T3] and/or thyroxine [T4]) from an abnormally functioning thyroid gland (Mooney 2010). Approximately $97-99 \%$ of cases result from benign nodular hyperplasia, adenomatous hyperplasia or adenoma of the thyroid gland (Peterson et al. 1983). In $70-75 \%$ of cases, both thyroid glands are affected. Only one to three per cent of cases are caused by mild to moderately malignant thyroid carcinoma (Peterson et al. 1983). The disease has been reported in cats between eight months and 22 years of age with a mean age of 13 years (Peterson et al. 1994; Gordan et al. 2003). Only five percent of hyperthyroid cats are younger than ten years at time of diagnosis (Peterson et al. 1994). Clinically and histopathologically, the disease resembles toxic nodular goiter of humans, a disease of the elderly that is more common in iodine deficient areas (Edinboro, ScottMoncrieff, \& Glickman 2004). Over the past 33 years, the prevalence of thyroidal pathological abnormalities has steadily but dramatically increased in the worldwide cat population. Despite its frequency, the underlying cause(s) of the disorder is/are not known and thus it is unclear how to prevent it.

\subsection{Worldwide Prevalence}

Feline hyperthyroidism was first described in 1979 and 1980 by investigators in New York and Boston (Holtworth et al. 1980; Peterson et al. 1981). Before that time, although pathology studies had sometimes identified thyroid nodules or masses in cats, these had been found

\footnotetext{
*The basis of this literature review has previously been published by the author (McLean, Lobetti \& Schoeman 2014)
} 
uncommonly and were rarely (if ever) associated with clinical signs (Lucke 1964; Leav et al. 1976).

Since these initial descriptions, several studies have documented steady, yet increases in the prevalence of the disease in the cat population over time across the world; for example, from $0.3 \%$ in 1979 to $4.5 \%$ in 1985 in North America; from $0.1 \%$ in 1978-1982 to $2 \%$ in 1993-1997, also in North America; and from 0.2\% in 1987-1994 to 2.6\% in 1998 in Germany (Scarlett et al. 1998; Kraft \& Buchler 1999; Edinboro et al. 2004). This disorder is now not only recognised as the most common endocrinopathy of the cat, but also as one of the more frequently diagnosed disorders in small animal practice throughout North America, Western Europe, Australia, New Zealand and Japan (Olczak et al. 2005; Peterson and Ward 2007; Mooney 2010). Although a number of factors such as increased awareness, easier availability of thyroid hormone assays and aging of the cat population may have contributed to the increase in the diagnosis of feline hyperthyroidism, they are unlikely to solely account for the rapid and dramatic increase in prevalence of the disease (Edinboro et al. 2004).

Several epidemiological studies suggest that hyperthyroidism is more common in countries such as North America, the UK and Germany but less common in countries such as Hong Kong and those in Scandinavia (Sparkes 2012). However, it is difficult to directly compare results of these prevalence studies because of differences in inclusion and exclusion criteria and thus definitive evidence of true geographic variation is generally lacking (Sparkes 2012). Nevertheless, some studies have provided convincing evidence of genuine geographic variations.

In one study, the incidence of hyperthyroidism in cats over nine years of age was compared between veterinary clinics in the UK and in Spain over a three year period (Wakeling et al. 2005). Both had a similar prevalence of cats aged over nine years of age $(16.4 \%$ and $20.1 \%$ respectively) but there was a significant difference in incidence rates of $11.92 \%$ in the UK versus $1.5 \%$ in Spain.

The hospital prevalence among cats over eight years of age in an urban population in Germany was noted as $11.4 \%$ in a 2006 study (Sassnau 2006) while a Portuguese study in 2014 found a prevalence of $9 \%$ in cats over the age of ten years (Horspool \& Dias 2014). In Japan, a prevalence of $8.9 \%$ was reported in cats older than nine years 
(Miyamoto et al. 2002), but in Hong Kong, a prevalence of $3.93 \%$ was found in cats over ten years of age (De Wet et al. 2009) and a prevalence of 6\% in apparently healthy cats over nine years of age was reported in one study in the UK in 2011 (Wakeling et al. 2011), while a more recent UK study reported a prevalence of $8.7 \%$ in cats over ten years of age presenting to primary-care veterinary practices (Stephens et al. 2014). In a 2013 Irish study, a prevalence of $21 \%$ was reported in cats over ten years of age presenting to private clinics in the greater Dublin area (Gallagher \& Mooney 2013), while a 2014 Polish study reported a prevalence of $20.4 \%$ in cats over seven years of age in a cat population in Warsaw (Gojska-Zyger et al. 2014).

Prevalence studies have not yet been performed in South Africa, a geographic area where hyperthyroidism in cats has recently been observed and where reportedly the incidence appears to be increasing.

\subsection{Risk Factors}

Several epidemiological studies have attempted to identify potential risk factors for feline hyperthyroidism, but a single dominant factor has, to date, not been identified (Scarlett et al. 1998; Kass et al. 1999; Martin et al. 2000; Edinboro et al. 2004; Olczak et al. 2005; De Wet et al. 2009; Wakeling et al. 2009). This is largely due to the fact that most of the epidemiological studies performed have been retrospective in nature and thus a direct causal relationship could not be established between risk factors and disease (van Hoek et al. 2015). Genetic or hereditary factors, nutritional component(s) in cat food leading to metabolic thyroid dysfunction, or thyroid-disrupting compounds introduced into the environment or diet are the potential risk factors that have been closely investigated (Peterson \& Ward 2007).

The potential risk factors that these various studies have identified include living indoors, being female, living in multi-cat households, having dental disease (independent of age), being exposed to topical flea preparations and pesticides, using cat litter (not linked to living indoors), consuming certain flavours of canned foods (fish or liver and giblet flavour) and being a non-pure bred cat. However, all of the studies have failed to consistently identify these risk factors and thus their significance remains uncertain (Sparkes 2012). Nevertheless, a number of these studies have also 
identified a number of common factors, including increased risk with age, decreased risk in Siamese and Himalayan cats and increased risk in cats that consume canned cat food, especially pop-top canned food.

\section{Genetic or Hereditary Factors}

In studying the pathogenesis of feline hyperthyroidism, researchers have looked at a number of cellular and genetic factors including whether feline hyperthyroidism resembles human Graves' disease, the most common cause of hyperthyroidism in people. Grave's disease is an autoimmune disorder in which circulating antibodies (thyroid stimulating immunoglobulins (TSIs)) bind to TSH receptors and mimic TSH, thereby promoting thyroid hormone production and secretion (Moony 2002). Levels of TSIs are increased in people suffering from Graves' disease. However, three separate studies in which two different techniques were used, failed to show such TSIs in hyperthyroid cats (Peterson et al.1987; Kennedy et al.1989; Brown et al. 1992). Interestingly, increased titres of thyroid growth stimulating immunoglobulins (TGIs) have been demonstrated in hyperthyroid cats (Brown et al. 1992). These have also been found in a variety of human thyroid diseases. In cats, there is no correlation between thyroid function and TGI activity in vitro and their role in the pathogenesis of feline hyperthyroidism remains unclear (Mooney 2002).

The expression of stimulatory and inhibitory $G$ proteins has also been studied in feline hyperthyroidism. G proteins are activated following binding of TSH to its receptor and are part of the intracellular signaling processes, among them the signal to secrete thyroid hormones (Ward et al. 2005).

Both inhibitory and stimulatory $G$ proteins exist and the balance between these controls how much thyroid hormone is produced by the cell (Hammer et al. 2000; Peterson \& Ward 2007; Ward et al. 2010). Stimulatory G proteins result in an increase in cyclic adenosine monophosphate (cAMP) levels where as inhibitory G proteins result in a decrease in cAMP levels (Hammer et al. 2000; Peterson \& Ward 2007; Ward et al. 2010). If levels of cAMP are increased, there is increased cell activation and thyroid hormone production. One study showed that whilst expression of stimulatory $G$ proteins was the same from thyroid tissue from euthyroid and hyperthyroid cats, expression of inhibitory G proteins (Gi) was significantly lower in the 
hyperthyroid cats (Hammer et al. 2000; Ward et al. 2005). Another study, where expression of $G_{i 1}, G_{2}$ and $G_{i 3}$ in enriched membrane preparations from thyroid glands was quantified, demonstrated that a decrease in $\mathrm{G}_{\mathrm{i} 2}$ expression in particular decreases inhibition of adenyl cyclase and allows a relative increase in stimulatory G protein expression. This results in increased amounts of cAMP and upregulation of thyroid hormone production (Ward et al. 2005). In another more recent study however, that evaluated alteration in ligand-stimulated activity of $\mathrm{G}$ proteins in thyroid gland cells of hyperthyroid cats, ligand-stimulated activation of $\mathrm{G}$ proteins was the same in both hyperthyroid and euthyroid cats. Therefore, alteration in inherent stimulatory and inhibitory G proteins did not appear to be part of the pathogenesis of the disease in cats in this study (Ward et al. 2010).

Adenomatous thyroid tissue from hyperthyroid cats has also been demonstrated to retain its histopathogical appearance and continue to grow and function when transplanted into nude mice, thus confirming its autonomous nature (Peter et al. 1987). Additionally, thyroid cells from hyperthyroid cats, cultured in TSH-free media have been shown to continue to grow and function (Peter et al. 1991). Thus, it is clear that feline hyperthyroidism more closely resembles human toxic nodular goiter than Graves' disease. Somatic mutations of the TSH receptor gene are an important cause of human toxic nodular goiter in humans. Similarly, mutations affecting the TSH gene have been identified in some cats with hyperthyroidism including some mutations that have also been reported in human hyperthyroidism (Watson et al. 2005).

Abnormal oncogene expression has also been theorized to have a potential role in the pathogenesis of feline hyperthyroidism (Peterson \& Ward 2007). Proto-oncogenes are found in normal cells and overexpression could eventually lead to autonomous function.

One study where thyroid tissue of 28 hyperthyroid cats was examined for expression of the oncogenes c-ras, bc12 and the tumour suppressor gene p53 using immunohistochemistry, revealed overexpression of the c-ras protein (Merryman et al. 1999). Gain-of- function mutations in this oncogene may play a role in the development of adenomatous hyperplasia (Mooney 2010). 


\section{Environmental Chemicals}

Exposure to environmental chemicals (e.g. pesticides, herbicides) is known to induce thyroid abnormalities in other species (Brucker-Davis 1998). Chemicals applied directly to the cat or the cat's environment have been associated with increased risk of hyperthyroidism in some epidemiological studies (Olczak et al. 2005; Scarlett et al. 1988). Regular exposure of cats to topical flea control products was also shown to be associated with an increased risk of developing the disease. However, none of these studies were able to identify a specific commercial anti-flea product or ingredient associated with the risk.

\section{Cat Litter}

An association was also found between the use of cat litter and the development of hyperthyroidism (Kass et al. 1999). Moreover, no difference in risk was found among brands of litter, suggesting that any toxin or goitrogenic chemical present in the cat litter is common to most brands. In the absence of a clear explanation of the relation between litter use and hyperthyroidism, use of cat litter may simply be a marker for cats that primarily live indoors, receive better average care, enjoy longer lives and are more likely to reach the age at which cats develop the disease (Peterson \& Ward 2007).

\section{Dietary lodine and Selenium}

Because of the dietary association, several studies have attempted to implicate iodine in the cause and progression of the disease (Mumma et al. 1986; Johnson et al. 1992). It has been postulated that wide swings in daily iodine or even low or high intake of iodine may contribute to the development of thyroid disease in cats. Although circulating $\mathrm{fT}_{4}$ concentrations are acutely affected by varying iodine intake, more prolonged ingestion of high or low iodine diets has been shown to have no apparent effect on $\mathrm{fT}_{4}$ levels (Tarttelin et al. 1992). Therefore, the role that iodine plays in the development of the disease remains unknown. Dietary iodine may have a modulatory effect on circulating thyroid hormone, but neither iodine excess nor deficiency can explain the development of thyroid adenomatous hyperplasia or the autonomous nature of hyperthyroidism in cats (Peterson \& Ward 2007). 
Like iodine, selenium status could also potentially modify thyroid function. One study found no difference in selenium status in both euthyroid and hyperthyroid cats sampled from different geographical locations with high and low prevalence of hyperthyroidism, but did find that circulating selenium values in all cats in the study were approximately 5 times higher than values reported in either rats or humans (Foster et al. 2001). The reason for the high levels of selenium is unclear but may possibly be as a result of increased dietary intake in this species. The significance of this finding is however still not known.

\section{Other Goitrogenic Compounds}

Many other goitrogenic compounds can contribute to the development of adenomatous lesions in exposed cats (Mooney 2010). These may be of particular importance because most are metabolized by glucuronidation, a metabolic pathway particularly slow in the cat (Mooney 2010). Most commercial cat foods contain relatively high levels of goitrogenic compounds (e.g. phthalates), and cats can also be exposed to many goitrogens (e.g. resourcenel, polyphenols, polychlorinated biphenols, polybrominated diphenyl ethers and isoflavones) in the environment. (Peterson \& Ward 2007).

\section{Bisphenol A (BPA)}

The polyphenolic compound bisphenol A (BPA), a building block of the epoxy resins commonly used for lining the interior of metal food cans to prevent corrosion of the can, has been detected in 15 different canned cat foods (Moriyama et al. 2002). BPA is a chemical of concern as it is a known endocrine disruptor and has been associated with various adverse health effects, including thyroid dysfunction in humans (Patrick 2009). Some of the toxic effects of BPA may in fact derive from its structural similarity to thyroid hormone (Patrick 2009). Chronic exposure to BPA may affect thyroid function through a number of potential mechanisms.

BPA has been shown to directly bind to thyroid hormone receptors as well as acting to disrupt thyroid hormone action within cells by competitively displacing $\mathrm{T}_{3}$ from the receptor and thus suppressing activation of transcription of thyroid-regulated genes. By acting as a thyroid hormone receptor antagonist, BPA may work at the pituitary level to increase circulating TSH and thus lead to thyroid hyperplasia and ultimately goiter in susceptible cats (Peterson 2012). Exposure to BPA is thought to occur 
primarily through ingestion and it is well established that residual BPA monomers migrate into the can contents during processing and storage. Evidence of BPA contamination of canned foods for human use has been widely reported (Tsai 2006). In two studies evaluating pet foods, most of the dog and cat foods were found to contain measurable levels of BPA and one of these studies confirmed that the BPA in the food had in fact originated from the can coating (Schecter et al. 2010; Kang \& Kongo 2002). One large case-control study demonstrated an association between hyperthyroidism and cats fed from 'pop top' cans (Edinboro et al. 2004). Results of the study suggested that overall consumption of pop-top canned food at various times throughout a cat's life was associated with a greater risk of developing hyperthyroidism compared to feeding from pouches or sachets. Another case control study carried out in the USA also found that cats that preferred to eat certain flavours of canned cat food (fish flavour or liver and giblets flavour) were at a significantly greater risk of hyperthyroidism compared to cats that did not prefer these flavours (Martin et al. 2000).

\section{Soy Isoflavones}

Polyphenolic soy isoflavones, in particular, genistein and daidzein, have also been identified in almost $60 \%$ of cat foods tested and have been shown to have negative effects on the pituitary-thyroid axis in both humans and rats (Court \& Freeman 2002). They are commonly used as dietary supplements and as a low-cost source of protein. Virtually all dry and semi-moist foods containing soy protein have high isoflavone content in concentrations adequate to interfere with thyroid function and decrease synthesis of thyroid hormones (Doerge \& Sheehan 2002). Soy isoflavones inhibit the activity of thyroid peroxidase, a key enzyme in the synthesis of thyroid hormones, which liberates iodine for addition onto thyroglobulin for production of $T_{3}$ and $T_{4}$. They also inhibit 5'-deiodinase activity, the enzyme that converts $\mathrm{tT}_{4}$ into the biologically active $\mathrm{T}_{3}$.

By blocking the production of thyroid hormones, TSH secretion will be increased, leading to thyroid hyperplasia and possibly goiter (Doerge \& Sheehan 2002). In a short-term feeding study (3 months) in clinically normal cats, cats receiving the soy diet had higher $\mathrm{tT}_{4}$ and $\mathrm{fT}_{4}$ concentrations, but total $\mathrm{T}_{3}$ concentrations remained unchanged (White et al. 2004). These results indicate that short-term feeding of soy 
to normal cats has a measurable, although modest effect on thyroid hormone homeostasis. Despite maintaining these normal hormone values, detectable urinary concentrations of the isoflavone genistein were found in 10 of the 18 cats in the study, suggesting that cats may have significant body burdens of this goitrogen. Of interest is studies in rats that demonstrate that feeding large amounts of soy isoflavones has little demonstrable effect on thyroid function. However, in the presence of iodine deficiency, feeding soy has been shown to readily inhibit thyroid hormone secretion and induce goiter. Thus feeding of soy can cause goiter, but only in animals or humans consuming diets that are relatively deficient in iodine or in those individuals who are otherwise predisposed to developing goiter because of exposure to other goitrogenic agents (lkeda et al. 2001).

\section{Polybrominated diphenyl ethers (PBDEs)}

Polybrominated diphenyl ethers (PBDEs) are synthetic bromide compounds that have been used as flame retardants in a variety of consumer products such as electronics, furniture and textiles for the past 30 years (Dye et al. 2007). Over the last 30 years they have also become major global and persistent organic contaminants that bioaccumulate in the environment, biomagnify up the food chain and have been found in significant amounts in both animals and humans (Costa et al. 2008). The chemical structure and properties of PBDEs is similar to those of polychlorinated biphenyls (PCBs) which were banned in the US in the late 1970's (Costa et al. 2008). Like PCBs, some of the toxic effects of PBDEs may derive from their structural similarities to thyroid hormones. Studies performed in rats, mice and humans have shown that PBDEs clearly disrupt thyroid hormone metabolism. In rats and mice, PBDEs lower free and $\mathrm{tT}_{4}$ concentrations in a dose-dependent manner, but have not been shown to affect circulating TSH concentrations (Hallgren et al. 2001; Zhou et al. 2001; Hallgren \& Darnerud 2002). Conversely, in humans, higher exposure to PBDEs has been shown to reduce serum TSH values and increase tT4 concentrations (Meeker et al. 2009). Reports of environmental contamination with PBDEs were also first published in 1979. This is coincident with the first veterinary case reports of feline hyperthyroidism and thus may play a role in the pathogenesis of the disease in this species (Dye et al. 2007). 
To date, multiple studies (three American and two Swedish) designed to determine whether body burdens of PBDEs in hyperthyroid cats was greater than those of nonhyperthyroid cats have shown that overall PDBEs levels in all cats are 20-100 fold greater than median levels found in human adults (Dye et al. 2000; Guo et al. 2012; Kupryianchyk et al. 2009; Norrgran et al. 2012; Mensching et al. 2012). None of the studies however, showed an association between hyperthyroid cats and high serum PBDEs levels. Meanwhile, two of the studies did show that serum PBDE concentrations in feral and outdoor cats are significantly lower than in client-owned and indoor cats, suggesting that house dust, rather than diet is the most likely route of exposure to PBDEs in household cats (Guo et al. 2012; Mensching et al. 2012). In a follow up study, investigators evaluated dust samples for PBDEs and found significantly higher PBDEs in dust from homes of hyperthyroid cats, compared with homes of euthyroid cats (Mensching et al. 2012). A significant correlation was also found between high dust PBDE values and high serum $\mathrm{tT}_{4}$ concentrations. Overall, these studies show that cats can be highly exposed to PBDEs, presumably through ingestion of household dust, during their normal grooming behavior. These findings also provide compelling evidence for the possible role of PBDEs in the development of thyroid tumours and hyperthyroidism in cats, though additional investigations are certainly warranted.

In addition to the above, there are many other goitrogens and thyroid disruptors (e.g. perchlorates, PCBs, resorcinol, dioxins, fluoride, F D\&C red dye \#3) that cats can be exposed to through their diet, drinking water or the environment that could contribute to the development of thyroid adenomatous hyperplasia and hyperthyroidism (Peterson 2012). Endocrine disruptors such as heavy metals (e.g. mercury) and chlorinated hydrocarbons (e.g. polyvinyl chloride and PCV) have been reported as contaminants in commercial cat canned food (Mumma et al. 1986). Such agents generally cause goiter by acting directly on the thyroid gland to reduce thyroid hormone synthesis. The resultant low circulating $\mathrm{tT}_{4}$ leads to an increased $\mathrm{TSH}$ secretion which, in turn, leads to thyroid enlargement (Peterson 2012). Other goitrogens, however, act indirectly to alter the regulator mechanisms of the thyroid gland or the peripheral metabolism and secretion of certain thyroid hormones (Peterson 2012). 


\subsection{Clinical Signs}

The clinical signs of hyperthyroidism vary in severity and cats are less symptomatic today compared with 15-20 years ago, presumably because of increased awareness and earlier diagnosis (Broussard et al. 1995; Shiel et al. 2007; Mooney 2010;). The disease is insidiously progressive and owners may consider mild signs as part of the generalised aging process. Consequently, months may pass before veterinary care is sought (Mooney 2010).

General features of the disease include weight loss (one of the most common clinical signs and seen in more than $80 \%$ of cats with the disease), hyperactivity, polyuria, polydipsia, unkempt hair coat and rarely muscle weakness and atrophy (Mooney 2010). Polyuria and polydipsia occurs in less than $50 \%$ of cats, but can be marked in some. Various mechanisms may be responsible including concurrent renal disease(a common problem in aged cats), increased renal blood flow, decreasing medullary solute concentration gradient, electrolyte abnormalities and primary polydipsia because of a hypothalamic disturbance induced by thyroid hormone excess (Mooney 2010). Cats showing depression, lethargy and reduced appetite are referred to as apathetic hyperthyroid cases and have traditionally accounted for less than $10 \%$ of all hyperthyroid cases (Mooney 2010). Some of these cats are overweight rather than thin and it has been suggested that most of them are suffering from either severe cardiac complications associated with their hyperthyroidism or have underlying neoplastic disease (Mooney 2010).

Gastrointestinal features of feline hyperthyroidism include polyphagia or anorexia (seen in apathetic hyperthyroidism), vomiting and less commonly diarrhoea (Mooney 2010). Rapid overeating may contribute to the vomiting in multi-cat households, although direct stimulation of the chemoreceptor trigger zone is also possible. Intestinal hypermotility, excess fat intake and a reversible reduction in pancreatic exocrine function all contribute to the diarrhoea seen in human hyperthyroidism, but many of these mechanisms have not yet been fully evaluated in cats (Mooney 2010).

Cardiovascular abnormalities are very common in cats with hyperthyroidism and are frequently the most significant findings on clinical examination (Mooney 2010;). Such abnormalities include tachycardia, audible heart murmurs, a gallop rhythm, increased apical pulse, rarely evidence of systemic hypertension (e.g. retinal detachment), left 
ventricular hypertrophy seen on echocardiography and evidence of congestive heart failure (e.g. dyspnoea, pulmonary crackles in cats with pulmonary oedema and/or a pleural effusion).

The overwhelming majority of hyperthyroid cats have a palpable goiter. Increasingly however, cats with 'cold' thyroid nodules have been identified (i.e. the presence of palpable thyroid nodules without detectable hyperthyroidism) (Bortetti et al. 2009). Many of these cats are in fact suffering from subclinical hyperthyroidism. It is now thought that most hyperthyroid cats go through a 1-3 year period of subclinical hyperthyroidism before developing overt hyperthyroidism (Wakeling et al. 2007; Wakeling et al. 2011). During this period, the cat has a total plasma $T_{4}$ concentration within the normal reference range in combination with persistently low levels of TSH $(<0.03 \mathrm{ng} / \mathrm{ml})$. Many of the cats later go on to develop hyperthyroidism, so close monitoring of these patients is justified (Wakeling et al. 2007).

\subsection{Diagnosis}

Since hyperthyroid cats are far less symptomatic than in the past, there has been a change in emphasis from simply confirming a diagnosis in a cat presenting with classical clinical signs to diagnosing hyperthyroidism in cats with few, if any, clinical signs or ruling the disease out in cats presenting with varied problems that may or may not be related to hyperthyroidism (Shiel \& Mooney 2007). This has a great impact on the efficacy of the diagnostic tests used, because the changes induced by hyperthyroidism become more subtle and the possibility of occult hyperthyroidism with or without concurrent disease becomes greater (Shiel \& Mooney 2007).

General screening laboratory tests, diagnostic imaging (echocardiography, radiography) and electrocardiography may provide supportive evidence of hyperthyroidism or detail the extent of cardiac involvement (Mooney 2010). Screening laboratory tests are also useful in eliminating other diseases with similar clinical signs or in depicting concurrent disorders potentially masked by hyperthyroidism, such as the presence of chronic renal disease, diabetes mellitus or neoplasia, which may be important in treatment decisions and ultimate prognosis (Mooney 2010). Changes found on routine screening tests include elevated activity levels of liver enzymes 
(alanine aminotransferace, (ALT) and alkaline phosphatase, (ALP), leukocytosis, eosinopenia and erythrocytosis (Mooney 2010 ). At least one of these liver enzyme activity levels is elevated in $90 \%$ of hyperthyroid cats (Shiel \& Mooney 2007). Mild hypokalaemia and hyperphosphataemia, in the absence of azotaemia, are also seen in a small number of affected cats (Mooney 2010). In most cats, the diagnosis can be confirmed by measuring resting serum $\mathrm{tT}_{4}$ (Caney 2012). The serum $\mathrm{tT}_{4}$ concentration is the sum of the protein-bound and free levels of $\mathrm{T}_{4}$ circulating in the blood and in most cats, hyperthyroidism can be diagnosed on the basis of high-resting serum $\mathrm{tT}_{4}$ concentration (Peterson et al. 1981; Graves \& Peterson 1994; Broussard et al. 1995). Measurement of serum $\mathrm{tT}_{4}$ by either radioimmunoassay (RIA) or chemiluminescent enzyme immunoassays (CEIAs) is more accurate than the in-clinic ELISA methods and are therefore the method of choice (Nelson 2003). Occasionally normal resting serum $\mathrm{tT}_{4}$ concentrations are recorded for cats with hyperthyroidism (Peterson \& Gamble 1990; Ferguson 1994). This could be due to within or between day variations in mildly affected animals (Broome et al. 1988; Ferguson 1994) or the effects of concurrent non-thyroidal illness (Peterson et al. 1990; McLoughlin et al. 1993; Mooney et al. 1996). Serum $\mathrm{tT}_{4}$ concentration thus has high specificity but low sensitivity as a diagnostic tool.

The calculated sensitivity of serum $\mathrm{fT}_{4}$ concentrations as a diagnostic test for hyperthyroidism is significantly higher (0.985) than the test sensitivity for $\mathrm{tT}_{4}$ concentration (0.913) (Peterson et al. 2001). But the specificity is significantly lower (0.937 compared to 1.0), which suggests that measurement of serum $\mathrm{fT}_{4}$ concentrations is not recommended as a sole diagnostic test for hyperthyroidism (Mooney et al. 1996; Peterson et al. 2001). Serum fT 4 is currently measured by one of two methods: RIA using kits designed for use in humans and a modified equilibrium dialysis (MED) technique that uses a short dialysis step to separate $\mathrm{fT}_{4}$ from proteinbound $\mathrm{T}_{4}$, followed by RIA for fT4. The MED technique is the most accurate method for determining serum $\mathrm{fT}_{4}$ concentrations, but is much more costly and is therefore often reserved for cats with suspected hyperthyroidism where $\mathrm{tT}_{4}$ values are borderline (Nelson 2003). An elevated $\mathrm{fT}_{4}(>50 \mathrm{pmol} / \mathrm{l})$ in addition to a tT4 in the upper half of the reference range $(>30 \mathrm{nmol} / \mathrm{l})$ is consistent with a diagnosis of hyperthyroidism (Wakeling et al. 2008). 
Use of canine TSH (cTSH) assays in cats has recently received attention in the diagnosis of feline hyperthyroidism. A reference range for $\mathrm{CTSH}$ of $0.03-0.15 \mathrm{ng} / \mathrm{ml}$ has been defined for older cats (Wakeling et al. 2008). In patients with subclinical and occult hyperthyroidism, cTSH levels are low or undetectable (Wakeling et al. 2007). Therefore if $\mathrm{tT}_{4}$ levels are in the upper half of the reference range $(>30 \mathrm{nmol} / \mathrm{l})$ and cTSH levels are low or undetectable $(<0.03 \mathrm{ng} / \mathrm{ml})$, hyperthyroidism is diagnosed (Wakeling et al. 2007). A recent study evaluating the usefulness of cTSH as a diagnostic test for feline hyperthyroidism using thyroid scintigraphy as the gold standard, concluded that measurement of serum cTSH concentration is a very sensitive, but nonspecific, diagnostic test with approximately $98 \%$ of hyperthyroid cats having serum cTSH concentrations that are suppressed below the limit of quantification ( $<0.03 \mathrm{ng} / \mathrm{ml}$ ) (Peterson et al. 2015) However, approximately $30 \%$ of the older euthyroid cats in that study also had undetectable serum cTSH concentrations. Unfortunately, the current commercial cTSH assay cannot accurately measure concentrations low enough to clearly distinguish between the low-normal serum cTSH concentrations found in some euthyroid cats from the truly low or totally suppressed concentrations found in most hyperthyroid cats. It was shown in that study that combining serum cTSH with $\mathrm{tT}_{4}$ or $\mathrm{fT}_{4}$ concentrations lowered the test sensitivity of cTSH from 98 to $97 \%$, but markedly increased overall test specificity (from 69.9 to $98.8 \%)$.The authors of the study concluded that testing in parallel by combining serum cTSH concentration with either $\mathrm{tT}_{4}$ or $\mathrm{fT}_{4}$ concentrations improved the ability to correctly differentiate hyperthyroid cats with occult or mild disease from euthyroid cats suspected of having thyroid disease, especially when serum concentrations of $\mathrm{tT}_{4}, \mathrm{~T}_{3}$, or $\mathrm{fT}_{4}$ were within the upper limits of their reference interval or only marginally increased.

Other options for diagnosis of difficult cases include dynamic thyroid tests (T3 suppression, TSH/TRH stimulations tests) and thyroid imaging (scintigraphy, ultrasound and CT). Dynamic thyroid tests are not always straightforward to interpret and are much less frequently performed, since they require multiple samples to be collected and may result in side-effects (Caney 2012). Scintigraphy is performed to test for hyperthyroidism by determining whether there is increased activity in the thyroid glands relative to the activity in the salivary glands 20-60 minutes after intravenous or subcutaneous injection of pertechnetate (Page et al. 2006). It is a very 
accurate and reproducible test used to differentiate between cats with unilateral, bilateral or multifocal disease (Page et al. 2006). It, however, requires access to specialist facilities and is not routinely available.

Ultrasonography has been used to document the dimensions and volume of the thyroid glands in euthyroid and hyperthyroid cats and has been shown to have $85,7 \%$ agreement with scintigraphy in defining normal and abnormal thyroid lobes (Shiel \& Mooney 2007). It is however technically demanding and very operator dependent. One study used helical CT to determine the dimensions and volume of thyroid tissue in clinically normal cats, however the value of such imaging in the diagnosis of hyperthyroidism remains undocumented (Shiel \& Mooney 2007). Although both CT and ultrasonography can provide information regarding thyroid volume and morphological information, including invasiveness and can guide sampling, they are unable to provide functional information and may not identify ectopic thyroid tissue or metastatic disease (Feeney \& Anderson 2007). 


\section{Chapter 2 \\ Objectives}

\subsection{Problem Statement}

- The prevalence of hyperthyroidism in older cats in South Africa is not known, despite anecdotal reports that the disease is less common than other endocrinopathies such as diabetes mellitus.

- South Africa is a cosmopolitan country with large numbers of pet owners as well as numerous pet shops. Although this implies that risk factors for the development of feline hyperthyroidism that have been identified in previous epidemiological studies could be present in the feline environment, no studies have been performed to describe the presence of potential risk factors in the relatively isolated South African cat population.

\subsection{Research Questions}

- What is the prevalence of hyperthyroidism in middle aged to older cats ( $\geq 9$ years) that are presented to general veterinary practices in South Africa?

- What are potential risk factors associated with the disease in South Africa?

\subsection{Benefits}

- The prevalence of feline hyperthyroidism in South Africa will be determined.

- This study will add to the knowledge of the geographic distribution and worldwide prevalence of feline hyperthyroidism.

- The presence of possible causative factors of feline hyperthyroidism in South Africa will be documented. 
- The research conducted fulfills part of the requirements of the principal investigator's MMedVet (Med) degree. 


\section{Chapter 3 \\ Materials and Methods}

\subsection{Experimental design}

A descriptive cross-sectional study aimed at describing the period prevalence as well as identifying associated risk factors of hyperthyroidism in cats in South Africa was performed. Although the design was based on random sampling, there was also a degree of stratification as this disease occurs mainly in older cats. Only cats that were presented by their owner for veterinary care were sampled and this may have caused some bias towards cats that are being fed the type of diets that have previously been implicated in contributing towards hyperthyroidism. In an attempt to avoid selection bias towards cats with hyperthyroidism and to ensure random sampling, it was also impressed on the veterinarians taking the samples that they were to sample all cats who met the inclusion criteria regardless of their own suspicions of the cat having the disease and regardless of the reason for the cat's visit.

Inclusion criteria:

- Cats 9 years or older

- Any sex

- Cats that had spent their whole life in South Africa

Exclusion criteria:

- Cats that presented in shock

- Cats that were on medication that could affect $T_{4}$ concentrations such as carbimazole, methylprednisolone, prednisolone, phenobarbitone, potassium bromide and sulpha-containing antibiotics

- Cats undergoing chemotherapy

- Fractious cats that precluded the taking of blood samples without sedation 


\subsection{Experimental Procedures}

Blood samples were taken from cats when they were presented to the veterinary clinics for either routine visits or health-related problems. Two to three millimeters of whole blood was collected from conscious cats by jugular venipuncture by qualified (and registered) veterinary surgeons or nurses.

Blood was then transferred to plain tubes and couriered on the same day to either the Johannesburg or Cape Town branches of Idexx laboratories, South Africa where it was centrifuged, the serum separated, aliquotted and frozen at $-20^{\circ} \mathrm{C}$. On a monthly basis, batches of samples were couriered to the clinical pathology laboratory at the Faculty of Veterinary Science, University of Pretoria to be stored at $-80^{\circ} \mathrm{C}$. At the end of the study period, all serum samples were analysed as a single batch to avoid interassay variation. Samples with an equivocal $\mathrm{tT}_{4}$ and undetectable cTSH were also couriered on dry-ice to the Nationwide Specialist Laboratories, Cambridge, UK for serum $\mathrm{fT}_{4}$ analysis.

The veterinarian to whom the animal was presented completed a questionnaire regarding the health status of the cat (Addendum A). The veterinarian or the veterinary assistant/nurse also assisted the owners in completing a second questionnaire regarding vaccination history, medical history, food and diet, flea control and environment of their cats (Addendum B). The owners were given a cover letter explaining the purpose of the sampling (Addendum C). Ethical approval for the study was also applied for and granted by the Animal Ethics Committee of the University of Pretoria (AEC number V103-13).

\subsection{Observations}

\subsubsection{Laboratory Tests}

Serum $\mathrm{tT}_{4}$ and $\mathrm{CTSH}$ concentrations were determined in all cats by use of a chemiluminescent competitive immunoassay (Immulite® 1000 Canine total T4, Siemens Medical Solutions Diagnostics) and a chemiluminescent immunometric assay (Immulite® 1000 Canine TSH, Siemens Medical Solutions Diagnostics) 
respectively. The reference interval for $\mathrm{tT}_{4}$ was $14-50 \mathrm{nmol} / \mathrm{L}$ and for $\mathrm{CTSH} 0$ $0.07 \mathrm{ng} / \mathrm{ml}$ (laboratories historical reference intervals). Serum $\mathrm{fT}_{4}$ concentrations were measured in cats with a serum $\mathrm{tT}_{4}$ concentration between $30-50 \mathrm{nmol} / \mathrm{L}$ and a serum cTSH concentration less than $0.03 \mathrm{ng} / \mathrm{ml}$ using equilibrium dialysis (Antech Diagnostics Inc ${ }^{\circledR}$ Free $T_{4}$ by Equilibrium Dialysis) with a reference interval of 10 $50 \mathrm{pmol} / \mathrm{L}$ (laboratories historical reference intervals). All cats with a serum $\mathrm{tT}_{4}$ concentration greater than $50 \mathrm{nmol} / \mathrm{L}$ or cats with a serum $\mathrm{tT}_{4}$ concentration between $30-50 \mathrm{nmol} / \mathrm{L}$, a serum cTSH concentration less than $0.03 \mathrm{ng} / \mathrm{ml}$ and a serum $\mathrm{fT}_{4}$ concentration greater than $50 \mathrm{pmol} / \mathrm{L}$ were classified as hyperthyroid.

\subsubsection{Variables- risk factors}

The following potential risk factors were evaluated:

- Age, breed and sex

- Vaccination status

- Environment (indoors or outdoors)

- Whether cat in single or multi-cat household

- Frequency of deworming and the preparation used

- Presence of chemicals in the environment - including flea control and preparation used

- Presence of commercial food in diet as well as percentage of dry and canned food

- Reason for visit

\subsubsection{Variables- clinical signs}

The presence of the following clinical signs were recorded:

- Weight loss

- Polyphagia 
- Heart rate

- Cardiac murmur

- Respiratory rate

- Vomiting

- Diarrhoea

- Palpable thyroid

\subsection{Statistical considerations}

A pre-study logistical regression power analysis was performed to determine sample size. A logistic regression of a binary response variable $(\mathrm{Y})$ on a binary independent variable $(X)$ with a sample size of 500 observations (of which $50 \%$ are in the group $X=0$ and $50 \%$ are in the group $X=1$ ) was shown to achieve $80 \%$ power at a 0.05 significance level to detect a change in probability $(Y=1)$ from the baseline value of 0.025 to 0.090 . This change corresponded to an odds ratio of 3.438 .

Statistical analysis was performed by Prof Peter Thompson, Section of Epidemiology, Faculty of Veterinary Science, University of Pretoria. Raw data was tabulated using Microsoft Excel. Prevalence of hyperthyroidism, with exact binomial $95 \%$ confidence intervals $(\mathrm{Cl})$, was calculated for all cats combined, for cats classified as healthy (no clinically significant disease identified) and for those classified as sick. Prevalence was compared between healthy and sick cats using a two-tailed Fisher's exact test.

Univariate associations between potential risk factors and hyperthyroidism were assessed using a two-tailed Fisher's exact test. Thereafter, all predictors were entered into a multiple logistic regression model to estimate their association with the odds of hyperthyroidism. Non-significant variables were eliminated until remaining variables were significant at $p=\leq 0.1$. To determine whether age should be included as a continuous or categorical variable, it was categorised into quantiles and the log odds of hyperthyroidism for each quantile was estimated using logistic regression. Since a monotonic change in estimated log odds was not seen with each suspensive quantile, age was modified as a categorical variable with three categories (9-11 years, 12-14 years and $>14$ years). The model was developed by backward elimination by successively dropping the least significant predictor until all remaining independent 
variables were significant in the model with $P$ WALD $\leq$ ) 0.1 . No interaction terms were assessed.

The fit of the final logistic regression model was assessed using the Hosmer Lemeshow goodness-of-fit test. Associations between clinical signs and hyperthyroidism were assessed on a univariate level using a two-tailed Fisher's exact test. All analyses were done using STATA version 14.1 (Stata Corporation, College Station, TX, USA). Statistical significance was set as $p=\leq 0.1$. This less stringent significance level was used as it was felt that this was an exploratory study which did not manage to include a large number of cases. 


\section{Chapter 4 \\ Results}

\subsection{Study population}

The study population consisted of a total of 302 cats that presented at participating veterinary practices between February 2014 and June 2015. The majority of the cats were sampled at two private veterinary practices in the Gauteng province of South Africa; namely the Bryanston Veterinary Hospital and Specialist Centre in Johannesburg (220 cats) and the Florida Veterinary Hospital in Krugersdorp (52 cats). The remaining cats were sampled at private veterinary practices in the Western Cape and Kwa-Zulu Natal provinces of South Africa; namely the Tygerberg Animal Hospital in Cape Town (23 cats) and the Hilton Veterinary Hospital (4 cats) and Westville Veterinary Hospital (3 cats) in Kwa-Zulu Natal.

Breeds represented included domestic shorthair (DSH) $(n=201)$, domestic longhair (DLH) $(n=29)$, Siamese and Siamese crosses $(n=26)$, Persian and Persian crosses $(n=10)$, Burmese $(n=10)$, Balinese $(n=s i x)$, Maine Coon and Maine Coon crosses ( $n=f i v e)$, domestic medium hair (DMH) ( $n=f o u r)$, Birman ( $n=t w o)$, Chinchilla ( $n=t w o)$, Norwegian forrest ( $n=t w o$ ) and one each of Abyssinian, British blue, ragdoll, Russian blue and Somali. There were 161 females and 141 males, of which 265 were sterilised. The ages of the cats ranged from 9-24 years with a median of 12 years.

Of the 302 cats, 118 cats were considered healthy and presented either for annual vaccinations (51 cats) or for routine visits (67 cats) while 184 were presented for various illnesses and considered sick.

\subsection{Laboratory results for study population}

The results of the $\mathrm{tT}_{4}$ measurements ranged between 1.31 and greater than $190 \mathrm{nmol} / \mathrm{L}$ with a mean concentration of $25.8 \mathrm{nmol} / \mathrm{L}$ and a median concentration of $26.5 \mathrm{nmol} / \mathrm{L}$. Twenty cats had a $\mathrm{tT}_{4}$ value $>50 \mathrm{nmol} / \mathrm{L}$ while 47 cats had a $\mathrm{tT}_{4}$ value between 30 - 
$50 \mathrm{nml} / \mathrm{L}$. Of the 47 cats with a $\mathrm{tT}_{4}$ value between $30-50 \mathrm{nmol} / \mathrm{L}, 21$ had a $\mathrm{CTSH}$ value $<0.03 \mathrm{ng} / \mathrm{ml}$; of which only one cat had a $\mathrm{fT}_{4}$ value $>50 \mathrm{pmol} / \mathrm{L}$. Only one of the cats with a $\mathrm{tT}_{4}$ value $>50 \mathrm{nmol} / \mathrm{L}$ had a cTSH value $>0.03 \mathrm{ng} / \mathrm{ml}$.

In total 21 cats were diagnosed as being hyperthyroid (tT $4>50 \mathrm{nmol} / \mathrm{L}$ or $\mathrm{tT}_{4}$ between $30-50 \mathrm{nmol} / \mathrm{L}$ with $\mathrm{cTSH}<0.03 \mathrm{ng} / \mathrm{ml}$ and $\mathrm{fT} 4>50 \mathrm{pmol} / \mathrm{L})$. Of the 21 hyperthyroid cats, 95\% had an undetectable cTSH.

\subsection{Laboratory results for hyperthyroid cats}

The signalment and laboratory values for the 21 hyperthyroid cats are shown in Table 1. There were 13 female and eight male cats, 19 of which were sterilised. Thirteen of the cats were DSH, four were DLH and one each was Balinese, $\mathrm{DMH}$, Main Coon and Siamese. Their ages ranged from 10-24 years with a median of 14 years. 
Table 1: $\quad$ Signalment and thyroid function in 21 hyperthyroid cats

\begin{tabular}{|c|c|c|c|c|c|c|}
\hline Cat no & Sex & Breed & Age(yrs) & $\begin{array}{c}\text { Total T }_{4} \\
(\mathrm{nmol} / \mathrm{L})^{1}\end{array}$ & $\begin{array}{c}\text { cTSH } \\
(\mathrm{ng} / \mathrm{ml})^{2}\end{array}$ & $\begin{array}{l}\text { Free } T_{4} \\
(p m / L)^{3}\end{array}$ \\
\hline $\mathrm{Br}-05^{\star}$ & $\mathrm{FI}$ & $\mathrm{DSH}$ & 13 & 56.8 & $<0.03$ & NA \\
\hline $\mathrm{Br}-13$ & $\mathrm{MN}$ & DSH & 12 & 61.3 & 0.075 & NA \\
\hline $\mathrm{Br}-50$ & $\mathrm{FN}$ & DSH & 10 & 56 & $<0.03$ & NA \\
\hline TB-33 & $\mathrm{MI}$ & $\begin{array}{l}\text { Maine } \\
\text { Coon }\end{array}$ & 17 & 79.9 & $<0.03$ & NA \\
\hline $\mathrm{Br}-67$ & $\mathrm{MN}$ & DSH & 17 & 81 & $<0.03$ & NA \\
\hline TB-73 & $\mathrm{FN}$ & DSH & 14 & $>193$ & $<0.03$ & NA \\
\hline $\mathrm{Br}-88$ & $\mathrm{FN}$ & $\mathrm{DMH}$ & 12 & 80.3 & $<0.03$ & NA \\
\hline $\mathrm{Br}-100$ & $\mathrm{MN}$ & DLH & 24 & $>193$ & $<0.03$ & NA \\
\hline Br-109 & $\mathrm{FN}$ & DSH & 14 & 133 & $<0.03$ & NA \\
\hline $\mathrm{Br}-110$ & $\mathrm{FN}$ & Balinese & 13 & 147 & $<0.03$ & NA \\
\hline $\mathrm{Br}-115$ & $\mathrm{MN}$ & $\mathrm{DSH}$ & 14 & $>193$ & $<0.03$ & NA \\
\hline $\mathrm{Br}-118^{*}$ & $\mathrm{MN}$ & $\mathrm{DSH}$ & 15 & 75.8 & $<0.03$ & NA \\
\hline $\mathrm{Br}-144^{*}$ & $\mathrm{MN}$ & DLH & 12 & 77.2 & $<0.03$ & NA \\
\hline $\mathrm{Br}-146$ & $\mathrm{FN}$ & $\mathrm{DSH}$ & 15 & 79.3 & $<0.03$ & NA \\
\hline $\mathrm{Br}-166$ & $\mathrm{FN}$ & DSH & 10 & 71.2 & $<0.03$ & NA \\
\hline $\mathrm{Br}-173^{*}$ & $\mathrm{FN}$ & DLH & 16 & 123 & $<0.03$ & NA \\
\hline $\mathrm{Br}-181$ & $\mathrm{FN}$ & Siamese & 14 & 60 & $<0.03$ & NA \\
\hline $\mathrm{Br}-183$ & $\mathrm{FN}$ & $\mathrm{DSH}$ & 10 & 40.3 & $<0.03$ & 52 \\
\hline HL-03* & $\mathrm{FN}$ & $\mathrm{DSH}$ & 18 & 90.3 & $<0.03$ & NA \\
\hline FL-54* & $\mathrm{FN}$ & DLH & 15 & $>193$ & $<0.03$ & NA \\
\hline FL-58 & MN & $\mathrm{DSH}$ & 13 & 62.9 & $<0.03$ & NA \\
\hline
\end{tabular}

$\mathrm{N}=$ neutered, $\mathrm{I}=$ intact, $\mathrm{F}=$ female, $\mathrm{M}=$ male, $\mathrm{NA}=$ not tested. Reference intervals:

${ }^{1}$ Total T4 14-50nmol/l, ${ }^{2} \mathrm{CTSH} 0-0.07 \mathrm{ng} / \mathrm{ml}$; ${ }^{3}$ Free $\mathrm{T}_{4}$ 10-50 pm/l.

${ }^{*}$ Considered healthy at time of sampling 


\subsection{Prevalence of hyperthyroidism in study population}

The prevalence of hyperthyroidism within the entire study population was $7.0 \%$ [95\% $\mathrm{Cl}: 4.4,10]$ with no significant difference in prevalence between healthy $(5.1 \%[1.9$, 11]) and sick (8.2\% $[4.6,13])$ cats (Table 2$)$.

Table 2: $\quad$ Prevalence of hyperthyroidism in 302 cats

\begin{tabular}{cccc}
\hline & $\mathbf{N}$ & Prevalence (\%) & $\mathbf{9 5 \%} \mathbf{C l}$ \\
\hline Sick cats & $15 / 184$ & 8.1 & $4.6-13.1$ \\
Healthy cats & $6 / 118$ & 5.1 & $1.9-10.7$ \\
Total & $21 / 302$ & 7.0 & $4.4-10.4$ \\
\hline
\end{tabular}

$\mathrm{n}=$ number cats

\subsection{Risk factors}

\subsubsection{Univariable analysis}

Univariable associations between potential risk factors and the development of hyperthyroidism are summarised in Table 3. 
Table 3: Univariable analysis of risk factors for hyperthyroidism

\begin{tabular}{|c|c|c|c|c|c|}
\hline \multirow{2}{*}{ Variable } & \multirow{2}{*}{ Category } & \multirow{2}{*}{$\mathrm{N}$} & \multicolumn{3}{|c|}{ Hyperthyroid cats } \\
\hline & & & $\mathrm{n}$ & $\%$ & $P$ \\
\hline \multirow[t]{3}{*}{ Age } & $9-11$ years & 121 & 3 & 2.5 & \multirow{3}{*}{0.03} \\
\hline & $12-14$ years & 93 & 10 & 10.8 & \\
\hline & $>14$ years & 88 & 8 & 9.1 & \\
\hline \multirow[t]{2}{*}{ Sex } & Female & 161 & 13 & 8.1 & \multirow[t]{2}{*}{0.50} \\
\hline & Male & 141 & 8 & 5.7 & \\
\hline \multirow[t]{7}{*}{ Breed } & DSH & 201 & 13 & 6.5 & \multirow{7}{*}{0.62} \\
\hline & DLH & 29 & 4 & 13.8 & \\
\hline & $\begin{array}{c}\text { Siamese/Siamese } \\
\text { Crosses }\end{array}$ & 26 & 1 & 3.9 & \\
\hline & $\begin{array}{l}\text { Persian/Persian } \\
\text { Crosses }\end{array}$ & 10 & 0 & 0 & \\
\hline & Burmese & 10 & 0 & 0 & \\
\hline & Balinese & 6 & 1 & 16.7 & \\
\hline & Other breeds & 20 & 2 & 0.1 & \\
\hline \multirow{3}{*}{$\begin{array}{l}\text { Number of cats in } \\
\text { household }\end{array}$} & 1 & 94 & 8 & 8.5 & \multirow{3}{*}{0.78} \\
\hline & 2 & 104 & 7 & 6.7 & \\
\hline & $2>$ & 104 & 6 & 5.8 & \\
\hline \multirow[t]{3}{*}{ Vaccinated } & Yes & 270 & 20 & 7.4 & \multirow{3}{*}{0.72} \\
\hline & No & 18 & 0 & 0 & \\
\hline & Not sure & 14 & 1 & 7.1 & \\
\hline \multirow[t]{2}{*}{ Dewormed } & Yes & 274 & 20 & 7.3 & \\
\hline & No & 18 & 0 & 0 & 0.44 \\
\hline
\end{tabular}


Not sure

Flea control

\section{Exclusively} Indoors

Canned food in diet

Hunter

Water
Yes

No

Not sure

$$
\text { Yes }
$$

No

$$
\text { Yes }
$$

No

Yes

No

Tap unboiled

Tap boiled

Mineral
10

139

162

1

246

56

71

231

120

182

256

32

14
1

10

5.8

13

8.0

0.54

0

0

7.3

0.78

3

5.4

11.3

0.11

13

5.6

6.7

1

$\mathrm{N}=$ number of cats in study population, $\mathrm{n}=$ number of hyperthyroid cats, $\mathrm{P}=\mathrm{P}$-value for twotailed Fisher's exact test

Although the prevalence of hyperthyroidism within the female population of cats $(13 / 161$ cats $-8 \%)$ was higher than that in the male population of cats (8/141 cats- $6 \%)$, the difference was not statistically significant. Likewise, the proportion of non-purebred cats that were hyperthyroid (18/241 cats- $8 \%$ ) was higher than that of purebred cats ( $3 / 61$ cats $5 \%)$. It was also found that the proportion of Siamese and Siamese cross cats with hyperthyroidism (1/26 cats-3.8\%) was lower compared to that of all other breeds (20/276 cats $-7.2 \%)$ The differences, however, were again not statistically significant. No statistically significant relationships between vaccinations, parasite control or indoor environment and hyperthyroidism were observed. 


\subsubsection{Multivariate analysis}

Only age and the presence of canned food in the diet were retained in the final logistic regression model of risk factors (Table 4$)$. Cats $\geq 12$ years of age (OR=4.3 $[95 \% \mathrm{Cl}$ : $1.2,15], p=0.02)$ and cats with canned food in their diet ( $\mathrm{OR}=2.1$ [95\% Cl: $0.8,5.4$ ], $\mathrm{p}=0.1$ ) were more likely to be diagnosed with hyperthyroidism.

Table 4: $\quad$ Final logistic regression model of risk factors for hyperthyroidism

\begin{tabular}{ccccc}
\hline Variable & Category & OR & $\mathbf{9 5 \%} \mathbf{C l}$ & $\mathbf{P}$ \\
\hline \multirow{2}{*}{ Age } & $<12$ years & 1.00 & - & - \\
& $>12$ years & 4.31 & $1.24-15.12$ & 0.02 \\
Canned food in & No* & 1.00 & - & - \\
diet & Yes & 2.1 & $0.822-5.36$ & 0.1 \\
\hline
\end{tabular}

${ }^{\star}$ Reference category

\subsection{Historical and clinical findings}

Of the six hyperthyroid cats that were considered healthy, one was presented for routine vaccinations and the other five were presented for routine health checks with no overt systemic signs. Of the 15 hyperthyroid cats that were considered sick, six had gastro-intestinal signs (vomiting and/or diarrhoea), three had dental disease, two presented for weight loss and/or anorexia; and four presented for cutaneous neoplasia, dyspnoea, PU/PD or bite wounds (1 of each).

Table 5 lists the frequency of the main clinical features in the hyperthyroid cats. Weight loss and vomiting were the most common findings, followed by tachypnoea, tachycardia, presence of a cardiac murmur and polyphagia. Clinical features typically associated with hyperthyroidism were only noted in 14 of the 21 hyperthyroid cats and 
detection of a goitre by the attending veterinary surgeon was only reported in 2 cases. The mean $\mathrm{tT}_{4}$ concentration in the group of hyperthyroid cats with clinical signs was $114 \mathrm{nmol} / \mathrm{L}$ (range $56-193 \mathrm{nmol} / \mathrm{L}$ ), whilst in the group of hyperthyroid cats without clinical signs this value was $79 \mathrm{nmol} / \mathrm{L}$ (range $40.3-193 \mathrm{nmol} / \mathrm{L}$ ).

\section{Table 5: $\quad$ Clinical features in 21 hyperthyroid cats}

\section{Finding Number of cats}

Weight loss

12

Vomiting

Tachypnoea

Tachycarida (>240bpm)

Polyphagia

Cardiac murmur

Diarrhoea

Palpable thyroid lobe
7

4

3

3

3

2

2

\subsubsection{Univariable analysis}

Univariable analysis (Table 6) for these clinical signs as predictors of hyperthyroidism demonstrated that hyperthyroid cats were more likely to present with weight loss $(\mathrm{OR}=3.2$ [95\% Cl: 1.2, 8.9], $\mathrm{p}=0.01)$ and with a heart rate $\geq 200 \mathrm{bpm}(\mathrm{OR}=5$ [95\% Cl: $1.7,16.1], p=0.01)$ than cats without the disease. 
Table 6: Univariate analysis of clinical signs associated with hyperthyroidism

\begin{tabular}{|c|c|c|c|c|c|}
\hline \multirow{2}{*}{ Variable } & \multirow{2}{*}{ Category } & \multirow{2}{*}{$\mathbf{N}$} & \multicolumn{3}{|c|}{ Hyperthyroid cats } \\
\hline & & & $\mathbf{n}$ & $\%$ & $\mathbf{P}$ \\
\hline Weight loss & $\begin{array}{l}\text { Yes } \\
\text { No }\end{array}$ & $\begin{array}{c}95 \\
207\end{array}$ & $\begin{array}{c}12 \\
9\end{array}$ & $\begin{array}{c}12.63 \\
4.35\end{array}$ & 0.013 \\
\hline Polyphagia & $\begin{array}{l}\text { Yes } \\
\text { No }\end{array}$ & $\begin{array}{c}46 \\
256\end{array}$ & $\begin{array}{c}3 \\
18\end{array}$ & $\begin{array}{l}6.52 \\
7.03\end{array}$ & 1.00 \\
\hline Heart Rate & $\begin{array}{c}<200 \\
200-240 \\
>240\end{array}$ & $\begin{array}{c}193 \\
99 \\
10\end{array}$ & $\begin{array}{c}6 \\
12 \\
3\end{array}$ & $\begin{array}{c}3.11 \\
12.12 \\
30.00\end{array}$ & 0.001 \\
\hline Cardiac Murmur & $\begin{array}{l}\text { Yes } \\
\text { No }\end{array}$ & $\begin{array}{c}16 \\
286\end{array}$ & $\begin{array}{c}3 \\
18\end{array}$ & $\begin{array}{c}18.75 \\
6.29\end{array}$ & 0.090 \\
\hline $\begin{array}{c}\text { Respiratory } \\
\text { Rate }\end{array}$ & $\begin{array}{c}\text { Normal } \\
\text { Increased } \\
\text { Dyspnoeic }\end{array}$ & $\begin{array}{c}277 \\
23 \\
2\end{array}$ & $\begin{array}{c}17 \\
3 \\
1\end{array}$ & $\begin{array}{c}6.14 \\
13.04 \\
50.00\end{array}$ & 0.042 \\
\hline Vomiting & $\begin{array}{l}\text { Yes } \\
\text { No }\end{array}$ & $\begin{array}{c}75 \\
227\end{array}$ & $\begin{array}{c}7 \\
14\end{array}$ & $\begin{array}{l}9.33 \\
6.17\end{array}$ & 0.431 \\
\hline Diarrhoea & $\begin{array}{l}\text { Yes } \\
\text { No }\end{array}$ & $\begin{array}{c}12 \\
290\end{array}$ & $\begin{array}{c}2 \\
19\end{array}$ & $\begin{array}{c}16.67 \\
6.55\end{array}$ & 0.199 \\
\hline
\end{tabular}

$\mathrm{N}=$ number of cats in study population, $\mathrm{n}=$ number of hyperthyroid cats, $\mathrm{P}=\mathrm{P}$-value for two-tailed Fisher's exact test 


\section{Chapter 5 \\ Discussion}

It has been more than 35 years since feline hyperthyroidism was first described, yet the cause and pathogenesis of the disease is still unknown. The disease occurs mainly in middle-aged to older cats and it was thought at first that the increase in incidence observed was due to an increase in lifespan of cats, heightened awareness of the disease and increased availability of thyroid hormone assays. Researchers however, have since shown that the increase in incidence is independent of age (Taylor et al. 1989; Scarlett et al. 1998; Bruyette 2001; Edinboro et al. 2004) and subsequent studies have concentrated on uncovering an inciting or triggering factor in the environment of these cats. This factor had to be something that had been present in the environment of the cats at the time that the disease was initially reported. Although the disease was first reported in the United States, there had been numerous reports of the disease in many countries throughout the world and it is now clear that we are looking for a trigger factor that had managed to cross continents in a very short period of time.

The prevalence of feline hyperthyroidism has also been shown to differ between different geographical regions and it is not clear if this is due to an absence of the potential trigger factor in various regions or if it reflects differences in diagnosing and reporting of the disease between countries. If it is due to a true difference in disease prevalence then this may suggest a difference in the presence of a possible trigger factor. Anecdotally, feline hyperthyroidism appears to have only relatively recently been observed and reported in South Africa and the incidence of the disease appears to be on the increase. To date, no prevalence studies have been performed in South Africa and the purpose of this study was to determine the prevalence of hyperthyroidism in older cats in this area as well as to try and identify potential risk factors.

Both healthy and sick cats were sampled in this study to ensure that the results represent the true prevalence and are not affected by under-reporting or misdiagnosis. Feline hyperthyroidism causes various manifestations of disease by its effect on multiple organ systems and it was essential to include sick cats in this survey. 
As the disease can also be insidious and subclinical in onset, apparently healthy cats could also not be excluded from the study population.

Sampling sick cats for measurement of $\mathrm{tT}_{4}$ concentrations is, however, not without its own set of problems. A range of studies have demonstrated that the presence of nonthyroidal illness (NTI) can significantly decrease the serum $\mathrm{tT}_{4}$ concentration of hyperthyroid cats (Mcloughlin et al. 1993; Peterson et al. 2001). This can apparently normalise tT4 concentrations in a hyperthyroid cat with concurrent NTI, especially in cats with early or mild hyperthyroidism (Peterson and Gamble 1990).

Unlike previous prevalence studies, in this study serum $\mathrm{tT}_{4}$ and $\mathrm{cTSH}$ was tested in all cats and $\mathrm{fT}_{4}$ tested in cats that had a serum $\mathrm{tT}_{4}$ between 30 and $50 \mathrm{nmol} / \mathrm{L}$ and $\mathrm{a}$ $\mathrm{cTSH}<0.03 \mathrm{ng} / \mathrm{ml}$ in an attempt to detect hyperthyroid cats with early or subclinical disease or hyperthyroid cats with severe concurrent non-thyroidal illness. The cTSH assay has been used in the diagnosis of feline hyperthyroidism with a reference interval of $0,03-0,15 \mathrm{ng} / \mathrm{ml}$ for older cats (Wakeling et al. 2008). In patients with subclinical and occult hyperthyroidism, cTSH levels are often low or undetectable (Wakeling et al. 2007). One study that evaluated the usefulness of cTSH as a diagnostic test for feline hyperthyroidism using thyroid scintigraphy as the gold standard, concluded that measurement of serum cTSH concentration was a very sensitive, but nonspecific, diagnostic test with approximately $98 \%$ of hyperthyroid cats having serum cTSH concentrations suppressed below the limit of quantification $(<0.03 \mathrm{ng} / \mathrm{ml}$ ) (Peterson et al. 2015). Unfortunately, the current commercial cTSH assay cannot accurately measure concentrations low enough to clearly distinguish between euthyroid cats and hyperthyroid cats with suppressed concentrations. Combining serum cTSH with $\mathrm{T}_{4}$ or $\mathrm{fT}_{4}$ concentrations lowered the test sensitivity of cTSH from 98 to $97 \%$, but markedly increased overall test specificity (from 69.9 to $98.8 \%)$. Interestingly in our study, $95 \%$ of the hyperthyroid cats had an undetectable cTSH.

The prevalence of hyperthyroidism in this study population of older cats presenting to private veterinary clinics in South Africa was found to be $7 \%$. This is similar to the prevalence rates reported in older cat populations in Japan (Miyamoto et al. 2002) and Portugal (Horspool et al. 2014), higher than that reported in Hong Kong (De Wet et al. 2009) but less than that reported in the UK (Stephens et al. 2014) and Germany 
(Sassnau 2006). It is however difficult to make direct comparisons between the results of different prevalence studies, because of the different inclusion and exclusion criteria and study methods used. This current study does, however, support some geographic variation in the prevalence of the disease worldwide and that this variation could reflect differences in dietary, environmental and/or genetic factors. What is interesting to note is that the disease in the South African cat population appears much more prevalent than anecdotally thought. This may be due to lack of awareness of the disease in clinical practice or due to the fact that the disease may be presenting more often in the subclinical form in this region.

In this study, there was no difference in the prevalence of hyperthyroidism between cats that were considered healthy and those that were considered sick. This may suggest that the disease is currently under-diagnosed in South Africa and that its early manifestations are insidious and challenging to recognise because it is often confused with other diseases or normal ageing changes.

In this current study there was an increased risk of hyperthyroidism with increasing age, with cats older than 12 years of age being four times more likely to have the disease. This is consistent with previous studies (Olczak et al. 2005; De Wet et al. 2009; Wakeling et al. 2009), and also concurs that feline hyperthyroidism is a disease of middle-aged to old cats. Since chronicity is needed for goitrogens to promote genetic mutations in thyrocytes, it could be postulated that older cats will be more predisposed if indeed exposure to goitrogenic substances is one the risk factors for the disease (Van Hoek et al. 2015).

In this current study, the prevalence of hyperthyroidism within the female population of cats $(13 / 161$ cats $-8 \%)$ was higher than that in the male population of cats $(8 / 141$ cats- 6\%), but the difference was not statistically significant. Most of the previously published studies reported no sex predilection for feline hyperthyroidism (Peterson et al. 1981; Broussard et al. 1995; Scarlett et al. 1998; Kass et al. 1999). There were, however, two studies that showed a significantly higher prevalence of hyperthyroidism in female cats (Edinboro et al. 2004; Olczak et al. 2005), whereas in one study (Sassnau 2006), there were significantly more male than female cats affected. The lack of significance in this current study is likely because of the low numbers of hyperthyroid cats and the presence of other unmeasured confounding factors. 
Two previous epidemiological studies have shown that Siamese cats have a significantly lower risk of developing hyperthyroidism compared with other breeds (Scarlett et al. 1998; Kass et al. 1999) and three studies have demonstrated a protective effect in pure-bred cats (Olczak et al. 2005; De Wet et al. 2009; Wakeling et al. 2009). In our study the proportion of non-purebred cats that were hyperthyroid (18/241 cats- $8 \%$ ) was higher than that of purebred cats ( $3 / 61$ cats $5 \%$ ). It was also found that the proportion of Siamese and Siamese cross cats with hyperthyroidism (1/26 cats- $3.8 \%)$ was lower compared to that of all other breeds (20/276 cats 7.2\%).The differences, however, were again not statistically significant.

The present study and four previous studies (Scarlett et al. 1998; Kass et al. 1999; Martin et al. 2000; Edinboro et al. 2004) all identified an increased risk of hyperthyroidism associated with an increased proportion of canned cat food in the diet. One study incriminated particular flavours of canned food (fish, liver and giblets) (Martin et al. 2000) and another incriminated cans with plastic linings and easy-open (pop-top) lids (Edinboro et al. 2004). Biologically plausible explanations for an association between feeding canned foods, especially of certain flavours, and hyperthyroidism may relate to the iodine content of canned vs dry cat foods (Johnson et al. 1992; Tartellin et al. 1992) (although the role that iodine plays in development of the disease is still largely unknown), or the presence in the canned food of the thyroid disruptors such as BPA, PBDEs or flavonoids (van Hoek et al. 2015). However, all these nutritional causes and risk factors remain speculative and lifelong prospective longitudinal studies are needed to properly investigate the role nutritional risk factors have in the development of hyperthyroidism (van Hoek et al. 2015).

In this study, clinical features typically associated with hyperthyroidism (weight loss, increased heart rate, polyphagia, vomiting etc.) were only noted in 14 of the 21 hyperthyroid cats and detection of a goitre by the attending veterinary surgeon was only reported in 2 cases. Thus 7 of the 21 hyperthyroid cats had no clinical signs. The most common clinical presentation was weight loss (12/21 cats) and vomiting (7/21 cats), which concurs with previous studies (Holzworth et al. 1980; Hoenig et al. 1982; Peterson et al. 1981; Thoday and Mooney 1992). Only 14\% of owners reported that their cats had an increase in appetite which is less than expected. In most of the reports this was the second most common clinical sign. Nine of the hyperthyroid cats (43\%) presented with gastro-intestinal signs- vomiting or diarrhoea or both. The lack 
of a palpable thyroid nodule in 19 of the 21 hyperthyroid cats was unexpected as 80 $90 \%$ of hyperthyroid cats usually have a palpable thyroid nodule (Holzworth et al. 1980; Heonig et al. 1982; Thoday and Mooney 1992; Broussard et al. 1995). The reason for this could be due to inexperience of the veterinarians or lack of thyroid enlargement due to an early or subclinical form of the disease.

The lack of characteristic clinical signs in some of the hyperthyroid cats could be due to the presence of a mild or early form of the disease (mean tT4 concentration of $114 \mathrm{nmol} / \mathrm{L}$ in group of cats with clinical signs vs $79 \mathrm{nmol} / \mathrm{L}$ in group of cats without clinical signs), but could also be due to lack of awareness of the disease by practitioners in South Africa due to their preconceived impression that the disease is not very prevalent in the South African cat population. It is furthermore possible that the lack of clinical signs in some cats reflects the status that existed in the USA prior to 1979 , when veterinarians first became aware of feline hyperthyroidism as a syndrome. Several reports from the time demonstrated that although the presence of thyroid adenomas on pathology were relatively high prior to 1979 , the majority of affected cats lacked recognisable clinical signs and most of the thyroids of affected cats were not grossly enlarged (Scarlett et al. 1998; Gerber et al. 1994; Scarlett 1994). Despite the absence of recognisable clinical signs in some cats, this study showed that hyperthyroidism needs to be considered in any older cat demonstrating weight loss or a heart rate $\geq 200 \mathrm{bpm}$ ).

The present study had some limitations that need to be considered. The low prevalence of hyperthyroidism, combined with the limited sample size, made it difficult to compare the group of hyperthyroid cats with the non-hyperthyroid cats. Bias may have been present as the study only included cats that were brought to veterinary practices. Although this bias may have influenced the risk factors identified in the study, it most likely had very little bearing on the prevalence of the disease reported as the veterinarian is only interested in the probability of encountering the disease in private practice. Likewise a degree of selection bias towards cats with hyperthyroidism may have been present owing to the fact that the veterinarian may have selected a cat based on the fact that they suspected the disease to be present (but were not convinced enough to order tests that the client had to pay for). It could be argued that even with in the healthy cat population, a veterinarian may be more inclined to select patients based on a suspicion that they may have hyperthyroidism. In addition, the 
study may have made the veterinarians selecting the cats more aware of hyperthyroidism, and thus may have contributed to this selection bias. An attempt was made to reduce selection bias however, by impressing on the veterinarians taking the samples that they were to sample all cats who met the inclusion criteria regardless of their own suspicions of the cat having the disease and regardless of the reason for the cat's visit. Likewise it must be reiterated that risk association studies are inherently flawed, because comparison of odds shows association only, and does not necessarily infer causality. 


\section{Chapter 6 Conclusion}

Feline hyperthyroidism appears to be a relatively common disease in older cats presenting to private veterinary clinics in South Africa. Hyperthyroidism needs to be considered in any older cat demonstrating weight loss or a heart rate $\geq 200$ in this cat population. The risk factors for development of feline hyperthyroidism identified in South Africa's relatively isolated population of cats appear to be somewhat similar to those that have been identified elsewhere. 


\section{References}

1. Boretti, F.S., Sieber-Ruckstuhl, N.S., Gerber, B., et al., 2009, Thyroid enlargement and its relationship to clinicopathological parameters and $\mathrm{T}_{4}$ status in suspected hyperthyroid cats, Journal of Feline Medicine and Surgery 11, 286-292.

2. Brown, R.S., Keating, P., Livingston, P.G., et al., 1992, Thyroid growth immunoglobulins in feline hyperthyroidism, Thyroid 2, 125-130.

3. Broome, M.R., Feldman, E.C. \& Turrel, J.M., 1988, Serial determination of thyroxine concentrations in hyperthyroid cats, Journal of the American Veterinary Medical Association 192, 49-51.

4. Broussard, J.D., Peterson, M.E. \& Fox, P.R., 1995, Changes in clinical and laboratory findings in cats with hyperthyroidism from 1983 to 1993, Journal of the American Veterinary Medical Association 206, 302-305.

5. Brucker-Davis, F., 1998, Effects of environmental synthetic chemicals on thyroid function, Thyroid 8, 827-856.

6. Bruyette, D.S., 2001, Feline endocrinology update, Veterinary Clinics of North America: Small Animal Practice 31, 1063-1081.

7. Costa, L.G., Giordono, G., Tagliaferri, S., et al., 2008, PDBE flame retardants: environmental contamination, human body burden and potential adverse effects, Acta Biomaterialia 79, 172-183.

8. Court, M.H. \& Freeman, L.M., 2002, Identification and concentration of soy isoflavones in commercial cat foods, American Journal of Veterinary Research 63, 181-185.

9. De Wet, C.S., Mooney, C.T., Thomson, P.N. \& Schoeman, J.P., 2009, Prevalence of and risk factors for feline hyperthyroidism in Hong Kong, Journal of Feline Medicine and Surgery 11, 315-321.

10.Doerge, D.R. \& Sheehan, D.M., 2002, Goitrogenic and estrogenic activity of soy isoflavones, Environmental Health Perspectives 110, 349-353. 
11. Dye, J.A., Venier, M., Zhu, L., et al., 2007, Elevated PBDE levels in pet cats: sentinels for humans?, Environmental Science and Technology 41, 6350-6356.

12. Edinboro, C.H., Scott-Moncrieff, J.C. \& Glickman, L.T., 2004, Environmental risk factors for feline hyperthyroidism: pet cats as potential sentinels for public health, Thyroid 14, 759.

13. Edinboro, C.H., Scott-Moncrieff, J.C., Janovitz, E., et al., 2004, Epidemiologic study of relationships between consumption of commercial canned food and risk of hyperthyroidism in cats, Journal of the American Veterinary Medical Association 224, 879-886.

14. Feeney, D.A. \& Anderson, K.L., 2007, Nuclear imaging and radiation therapy in canine and feline thyroid disease, Veterinary Clinics of North America: Small Animal Practice 37, 799-821.

15. Ferguson, D.C., 1994, Pathogenesis of feline hyperthyroidism, in August, J. (ed.), Consultations in Feline Medicine, pp 136-137, W. B. Saunders, Philadelphia.

16. Foster, D.J., Thoday, K.L., Arthur, J.R. et al., 2001, Selenium status of cats in four regions of the world and comparison with reported incidence of hyperthyroidism in cats in those regions, American Journal of Veterinary Research 62, 934-937.

17. Gallagher, B. \& Mooney, C.T. 2013, Prevalence and risk factors for hyperthyroidism in Irish cats from the greater Dublin area, Journal of Veterinary Internal Medicine 27, 689.

18. Gerber, H., Peter, H., Ferguson, D.C. \& Peterson, M.E., 1994, Etiopathology of feline toxic nodular goitre, Veterinary Clinics of North America: Small Animal Practice 24, 541-565.

19. Gojska-Zygner, O., Lechowski, R. \& Zygner, W., 2014, Prevalence of feline hyperthyroidism in mature cats in urban population in Warsaw, Bulletin of the Veterinary Institute in Pulawy 58, 267-271.

20.Gordan, J.M., Ehrhart, E.J., Sisson, D.D. \& Jones, M.A., 2003, Juvenile hyperthyroidism in a cat, Journal of the American Animal Hospital Association 39, 67-71. 
21. Graves, T.K. \& Peterson, M.E., 1994, Diagnostic tests for feline hyperthyroidism, Veterinary Clinics of North America: Small Animal Practice 24, 567-576.

22. Guo W., Park, J.S., Wang, Y., Gardner, S., et al., 2012, High polybrominated diphenyl ether levels in Californian house cats: house dust a primary source?, Environmental Toxicology and Chemistry 31, 301-306.

23. Hallgren, S. \& Darnerud, P.O., 2002, Polybrominated diphenyl ethers (PBDEs), polychlorinated biphenyls (PCBs) and chlorinated paraffins (CPs) in rats testing interactions and mechanisms for thyroid hormone effects, Toxicology $177,227-243$.

24. Hallgren, S., Sinjari, T., Hakansson, H. \& Darnerud, P.O., 2001, Effects of polybrominated diphenyl ethers (PBDEs) and polychlorinated biphenyls (PCBs) on thyroid hormone and Vitamin A levels in rats and mice, Archives of Toxicology 75, 200-208.

25. Hammer, K.B., Holt, D.E. \& Ward, C.R., 2000, Altered expression of G proteins in thyroid gland adenomas obtained from hyperthyroid cats, American Journal of Veterinary Research 61, 874-879.

26. Hoenig, M., Goldschmidt, M.H., Ferguson, et al., 1982, Toxic nodular goiter in the cat, Journal of Small Animal Practice 23, 1-12.

27. Holzworth, J., Theran, P. \& Carpenter, J.L., 1980, Hyperthyroidism in the cat: ten cases, Journal of the American Veterinary Medical Association 176, 345353.

28. Horspool, L.J.I \& Dias N.R., 2014, Prevalence of hyperthyroidism in Portuguese cats. In: Proceedings of the $24^{\text {th }}$ ECVIM-CA Congress, Mainz, Germany, September 4-6, pp. 198.

29. Ikeda, T., Nishikawa, A., Son, H.Y., et al., T., 2001, Synergistic effects of high dose-dose soy bean intake with iodine deficiency, but not sulpahadimethoxine or phenobarbital on rat thyroid proliferation, Japanese Journal of Cancer Research 92, 390-395.

30. Johnson, L.A., Ford, H.C., Tarttelin, M.F. \& Feek, C.M., 1992, lodine content of commercially-prepared cat foods, New Zealand Veterinary Journal 40, 18-20. 
31.Kang, J.H. \& Kondo, F., 2002, Determination of bisphenol A in canned pet foods, Research in Veterinary Science 73, 177-182.

32.Kass, P.H., Peterson, M.E., Levy, J.K., et al., L.D., 1999, Evaluation of environmental, nutritional and host factors in cats with hyperthyroidism, Journal of Veterinary Internal Medicine 13, 323-329.

33. Kennedy, R.L., Thoday, K.L. \& Mooney, C.T., 1989, Lack of thyroid stimulatory activity in the serum of hyperthyroid cats, Autoimmunology 3, 317-318.

34. Kraft, W. \& Buchler, F., 1999, Hyperthyroidism: incidence in the cat, Tierarztliche Praxis. Ausgabe K, Klientiere Heimtiere 27, 386-388.

35. Kupryianchyk, D., Hovender, L., Jones, B., et al., 2009, Hyperthyroidism, a new disease in cats- is it caused by exposure to environmental organic pollutants?, Organohalogen Compendium 71, 2720-2725.

36. Leav, I., Schiller, A.L., Rijnberk, A., et al., 1976, Adenomas and carcinomas of the canine and feline thyroid, American Journal of Pathology 83, 61-122.

37. Lucke, V.M., 1964, A histological study of thyroid abnormalities in the domestic cat, Journal of Small Animal Practice 5, 352- 358.

38. Martin, K.M., Rossing, M.A., Ryland, L.M., et al., W.A., 2000, Evaluation of dietary and environmental risk factors for hyperthyroidism in cats, Journal of the American Veterinary Medical Association 217, 853-856.

39. Mayer-Roenne, B., Goldstein, R.E. \& Erb, H.N., 2007, Urinary tract infections in cats with hyperthyroidism, diabetes mellitus and chronic kidney disease, Journal of Feline Medicine and Surgery 9, 124- 132.

40. McLean, J.L., Lobetti, R.G. \& Schoeman, J.P., 2014, Worldwide prevalence and risk factors for feline hyperthyroidism: a review, Journal of the South African Veterinary Association 85, 1097- 1103. 
41. McLoughlin, M.A., DiBartola, S.P., Birchard, S.J. \& Day, D.G., 1993, Influence of systemic nonthyroidal illness on serum concentration of thyroxine in hyperthyroid cats, Journal of the American Animal Hospital Association 29, 227-234.

42. Meeker, J.D., Johnson, P.I., Camman, D., et al., PBDE concentrations in house dust are related to hormone levels in men, Science of the Total Environment 407, 3423-3429.

43. Mensching, D.A., Slater, J., Scott, J.W., et al., 2012, The feline thyroid gland: a model for endocrine disruption by polybrominated diphenyl ethers (PBDEs)?, Journal of Toxicology and Environmental Health 75, 201-212.

44. Merryman, J.I., Buckles, E.L., Bowers, G., et al. 1999, Overexpression of c-Ras in hyperplasia and adenomas of the feline thyroid gland: an immunohistochemical analysis of 34 cases, Veterinary Pathology 36, 117-124.

45. Miyamoto, Y., Miyata, I. \& Kurobane, K., 2002, Prevalence of feline hyperthyroidism in Osaka and the Chugoku region, Journal of the Japanese Veterinary Medical Association 55, 289-292.

46. Mooney, C.T., 2002, Pathogenesis of feline hyperthyroidism, Journal of Feline Medicine and Surgery 4, 167-169.

47. Mooney, C.T., 2010, Hyperthyroidism in S. Ettinger \& E.Feldman (eds.), Textbook of veterinary internal medicine: Diseases of the dog and cat, pp. 1761-1779, WB Saunders, Philadelphia.

48. Mooney. CT., Little, C.J.L. \& Macrae \& A.W.,1996, Effect of illness not associated with the thyroid gland on serum total and free thyroxine concentrations in cats, Journal of the American Veterinary Medical Association 208, 2004-2008.

49. Moriyama, K., Tagami, T., Akamizu, T., et al., 2002, Thyroid hormone action is disrupted by bisphenol A as an antagonist, Journal of Clinical Endocrinology and Metabolism 87, 5185-5190.

50. Mumma, R.O., Rashid, K.A., Shane, B.S., et al., 1986, Toxic and protective constituents in pet foods, American Journal of Veterinary Research 47, 16331637. 
51. Nelson, R.W., 2003, Disorders of the Thyroid Gland in Nelson, R.W. \& Couto C.G. (eds.), Small Animal Internal Medicine, pp 691-728, Mosby, Philadelphia.

52. Norrgran, J., Jones, B., Lindquist, N.G. \& Bergman, A., 2012, Decabromobiphenyl, polybrominated diphenyl ethers and brominated phenolic compounds in serum of cats diagnosed with the endocrine disease feline hyperthyroidism, Archives in Environmental Contaminants and Toxicology 63, 161-168.

53. Olczak, J., Jones, B.R., Pfeiffer, D.U., et al., 2005, Multivariate analysis of risk factors for feline hyperthyroidism in New Zealand, New Zealand Veterinary Journal 53, 53-58.

54. Page, R.B., Scrivani, P.V., Dykes, N.L., et al., 2006, Accuracy of increase thyroid activity during pertechnetate scintigraphy by subcutaneous injection for diagnosing hyperthyroidism in cats, Veterinary Radiology and Ultrasound 47, 206-211.

55. Patrick, L., 2009, Thyroid disruption: mechanisms and clinical implications in human health, Alternative Medicine Review 14, 326-346.

56. Peter, H.J., Gerber, H., Studer, H. et al., 1987, Autonomy of growth and of iodine metabolism in hyperthyroid feline goiters transplanted onto nude mice, Journal of Clinical Investigation 80, 491-498.

57.Peter, H.J., Gerber, H., Studer, H., et al., 1991, Autonomous growth and function of cultured thyroid follicles from cats with spontaneous hyperthyroidism, Thyroid 1, 331-337.

58. Peterson, M. E., 2012, Hyperthyroidism in cats: what's causing this epidemic of thyroid disease and can we prevent it?, Journal of Feline Medicine and Surgery 14, 804-818.

59. Peterson, M.E., Guterl, J.N., Nichols, R. et al., 2015, Evaluation of serum thyroid-stimulating hormone concentration as a diagnostic test for hyperthyroidism in cats, Journal of Veterinary Internal Medicine 29, 13271334.

60. Peterson, M.E. \& Gamble, D.A., 1990, Effect of nonthyroidal illness on serum thyroxine concentrations in cats: 494 cases (1988), Journal of the American Veterinary Medical Association 197, 1203-1208. 
61.Peterson, M.E., Kintzer, P.P., Cavanagh, P.G., et al., 1981, Feline hyperthyroidism: pretreatment clinical and laboratory evaluation of 131 cases, Journal of the American Veterinary Medical Association 183, 103-110.

62. Peterson, M.E., Livingston, P. \& Brown, R.S., 1987, Lack of circulating thyroid stimulating immunoglobulins in cats with hyperthyroidism, Veterinary Immunology and Immunopathology 16, 277-282.

63. Peterson, M.E., Melian, C. \& Nichols, R., 2001, Measurement of serum concentrations of free thyroxine, total thyroxine, and total triiodothyronine in cats with hyperthyroidism and cats with nonthyroidal disease, Journal of the American Veterinary Medical Association 218, 529-536.

64.Peterson, M.E., Randolf, J.F. \& Mooney, C.T., 1994, Endocrine disease in R.G. Sherding (ed.), The cat: Diseases and clinical management, pp. 1416-1452, Churchill Livingstone, New York.

65. Peterson, M.E. \& Ward, C.R., 2007, Etiopathologic findings of hyperthyroidism in cats, Veterinary Clinics of North America: Small Animal Practice 37, 633-645.

66. Sassnau, R., 2006, Epidemiological investigation on the prevalence of feline hyperthyroidism in an urban population in Germany, Tierarztliche Praxis. Ausgabe K, Klientiere Heimtiere 34, 450-457.

67. Scarlett, J.M., 1994, Epidemiology of thyroid diseases of dogs and cats, Veterinary Clinics of North America: Small Animal Practice 24, 477-486.

68. Scarlett, J.M., Moise, N.S. \& Rayl, J., 1998, Feline hyperthyroidism: a descriptive and case control study, Preventative Veterinary Medicine 6, 295309.

69. Schecter, A., Malik, N., Haffner, D., et al., 2010, Bisphenol A in US food, Environmental Science and Technology 44, 9425-9430.

70. Shiel, R.E. \& Mooney, C.T., 2007, Testing for hyperthyroidism in cats, Veterinary Clinics of North America: Small Animal Practice 37, 671-691.

71. Sparkes, A. 2012, Where are we now? Historical and epidemiological aspects of feline hyperthyroidism in I Becvarova \& $\mathrm{H}$. Meyer (eds.), Feline 
hyperthyroidism: the rise and fall of thyroxine, Global symposium proceedings, Barcelona, Spain, May 9-11, 2012, pp. 5-8.

72. Stephens M.J., O'Neill D.G., Church D.B. et al., 2014, Feline hyperthyroidism reported in primary-care veterinary practices in England: prevalence, associated factors and spatial distribution, Veterinary Record 175, 458-462.

73. Taylor, S.J., Jacobs, R.M., Lumsden, J.H. \& Bonnett, B.M., 1989, Perspectives on the diagnosis of feline hyperthyroidism, Canadian Veterinary Journal 30, 447-481.

74. Tarttelin, M.F., Johnson, L.A., Cooke, R.R., et al., 1992, Serum free thyroxine levels respond inversely to changes in levels of dietary iodine in the domestic cat, New Zealand Veterinary Journal 40, 66-68.

75. Thoday, K.L. \& Mooney, C.T., 1992, Historical, clinical and laboratory features of 126 hyperthyroid cats, Veterinary Record 131, 257-264.

76. Tsai, W.T., 2006, Human health risk on environmental exposure to bisphenolA: a review, Journal of Environmental Science, Health, Environmental Carcinogens and Ecotoxicological Review 24, 225-255.

77. Van Hoek, I., Hesta, M. \& Biourge, V., 2015, A critical review of foodassociated factors proposed in the etiology of feline hyperthyroidism, Journal of Feline Medicine and Surgery 17, 837-847.

78. Wakeling, J., Elliott, J. \& Syme, H., 2011, Evaluation of predictors for the diagnosis of hyperthyroidism in cats, Journal of Veterinary Internal Medicine 25, 1057-1065.

79. Wakeling, J.M., Elliott, J. et al., 2008, Diagnosis of hyperthyroidism in cats with mild chronic kidney disease, Journal of Small Animal Practice 49, 287294.

80. Wakeling, J., Everard, A., Brodbel, D., et al., 2009, Risk factors for feline hyperthyroidism in the UK, Journal of Small Animal Practice 50, 406-414.

81. Wakeling, J., Melian, C. \& Font, A., 2005, Evidence for differing incidences of feline hyperthyroidism in London, UK and Spain, Proceedings of the $15^{\text {th }}$ ECVIM-CA Congress, Glasgow, Scotland, September 1-3, 2005, pp. 220. 
82. Wakeling, J., Smith, K., Scase, T., et al., 2007, Subclinical hyperthyroidism in cats: A spontaneous model of subclinical toxic nodular goiter in humans?, Thyroid 17, 1201-1209.

83. Ward, C.R., Achenbach, S.E., Peterson, M.E., et al., 2005, Expression of inhibitory $\mathrm{G}$ proteins in adenomatous thyroid glands obtained from hyperthyroid cats, American Journal of Veterinary Research 66, 1478-1482.

84.Ward, C.R., Windham, W.R. \& Dise, D., 2010, Evaluation of activation of G proteins in response to thyroid stimulating hormone in thyroid gland cells from euthyroid and hyperthyroid cats, American Journal of Veterinary Research 71, 643-648.

85. Watson, S.G., Radford, A.D., Kipar, A., et al., 2005, Somatic mutations of the thyroid-stimulating hormone receptor gene in feline hyperthyroidism: parallels with human hyperthyroidism, Journal of Endocrinology 186, 523-537.

86. White, H.L., Freeman, L.M., Mahony, O., et al., 2004, Effect of dietary soy on serum thyroid hormone concentrations in healthy adult cats, American Journal of Veterinary Research 65, 586-591.

87.Zhou, T., Ross, D.G., Devito, M.J. \& Crofton, K.M., 2001, Effects of short-termin-vivo exposure to polybrominated diphenyl ethers on thyroid hormones and hepatic enzymes in weanling rats, Toxicological Science 61, 76-82. 


\title{
Addendum A: Questionnaire Part I
}

\author{
Veterinarian Questionnaire
}

QUESTIONNAIRE - PART I (TO BE COMPLETED BY VETERINARIAN)

Date:

Name of Clinic:

Name of Vet:

Owner Name:

Client Reference:

Name of Cat:

\section{Reason for visit}

Routine Health Check

Vaccination

Illness (specify)

\section{Clinical examination findings}

Has the cat lost weight in the last 3 months?

Yes

No

Is the cat polyphagic?

Yes

No

Heart rate:

$<200$

200-240

$>240$

Is a cardiac murmur audible?

Yes

No

Respiratory rate: Normal

Increased

Dyspnoeic

Does the cat vomit?

Yes $\square \quad$ No

Does the cat have diarrhoea?

Yes

No

Are the thyroid glands palpable

No

Right only

Left only

Both 


\title{
Addendum B: Questionnaire Part II
}

\author{
Client Questionnaire
}

\section{QUESTIONNAIRE - PART II (TO BE COMPLETED BY OWNER)}

Owner name:

Name of cat:

Sex: Male $\square$ Female $\square \quad$ Neutered

Breed:

Age of cat / year of birth:

How long have you owned your cat? $<5$ yrs

$5-10 y r s \quad>10 y r s$

Number of cats in household:

1

2

$>2$

\section{Vaccination/worming history}

Is your cat vaccinated? Yes $\square$ No $\square$ Not sure $\square$ Frequency: Yearly $\square$ Infrequently

Is your cat dewormed? $\quad$ Yes $\quad \square$ No $\square$ Not sure $\square$ Frequency: Yearly $\square$ Infrequently

Brand of dewormer (if known)

Do you use parasiticides on your cat?

Type of preparation: Spot-on

Brand (if known)

How long have you been using parasiticides on your cat?

\section{Environment}

Does your cat live: strictly indoors $\square$ strictly outdoors $\square$ predominantly indoors predominantly outdoors

Diet / food

Is your cat fed: Commercial canned food $\square \quad$ Commercial dry food

Commercial semi-moist food $\quad \square$ Non-commercial food

Does your cat have a favourite brand/flavour that you use most frequently

Does your cat catch insects, rats or mice?

What type of water does your cat drink:

Distilled $\square$ Mineral $\square$ Tap water boiled $\square$ Tap water unboiled $\square$ Other 


\title{
Addendum C: Cover Letter
}

\section{INFORMED OWNER CONSENT AND INFORMATION FORM}

\section{Study to Determine the Prevalence of and Risk Factors for Feline Hyperthyroidism in South Africa}

\author{
Dr Joanne McLean BSC (Vet Biol) BVSc (Hons) \\ Bryanston Veterinary Hospital \\ PO Box 67092, Bryanston, 2021 \\ Email: joanne@fuseprop.co.za \\ Tel: (011) 7066023
}

\section{About Feline Hyperthyroidism}

Feline hyperthyroidism is the most common cause of disease in middle-aged and older cats in the United States and the United Kingdom. It is also very common in Europe, Australia and New Zealand.

The origins and causes of this disease are unknown. It has been suggested that immunological, infectious, nutritional, environmental or genetic factors may interact to cause pathological changes in the thyroid gland. To date nobody has been able to explain how these factors could cause the disease to develop in cats on different continents within a relatively short period. The variation in geographic incidence may reflect differences in dietary or environmental factors and a recent study found a significant association between feline hyperthyroidism and consumption of canned food.

Hyperthyroidism in cats is observed and reported in South Africa and its incidence seems to be on the increase.

\section{Purpose of the Study}

The aim of this study is to determine the presence of hyperthyroidism amongst cats in South Africa and to determine the environmental, nutritional or infectious agents that cats with the disease may be exposed to. These results may assist in preventing an increase in the incidence of this disease in South Africa.

\section{Eligibility for Participation}

Any cat over 9 years of age that has spent its entire life in South Africa is eligible to participate in this study. Cats that are in shock, are on certain medications that can alter thyroid function or cats that are too fractious to allow blood sampling without sedation will not be eligible for this study.

\section{Description of Procedures Performed on Study Participants}

Each cat will be examined by a veterinarian and their owner or an agent of the owner will be interviewed to determine questions about the cat's diet, environment and medical history. In addition, a veterinarian or veterinary nurse will obtain blood from a superficial vein using a syringe and needle. Approximately $3 \mathrm{ml}$ of blood will be collected.

\section{Expected Duration of Participation}

The entire process is expected to require no more than 30 minutes to collect blood, perform a physical examination and to fill in both the veterinarian and client questionnaires.

\section{Possible Discomforts and Risks}


Withdrawal of blood from a vein can lead to transient pain, swelling, bruising and in very rare cases, infection. Every effort will be made by the veterinarian/veterinary nurse obtaining the blood samples to prevent these complications.

\section{Possible Benefits of the Study}

The benefit to participating cat owners will be that their cats will be tested for hyperthyroidism free of charge. The results however may take up to 12 months to become available.

\section{Confidentiality}

Owner and patient confidentiality will be maintained. No identification of individuals shall be made when reporting or publishing the data arising from this study.

\section{Financial Obligations}

There are no financial obligations to the owners from the principle investigator, the veterinary prectice where samples will be taken, or the University of Pretoria for participating in this study.

\section{Liability}

Neither the University of Pretoria, the principle investigator, the private veterinary practices participating in this study nor any of their associated employees can be held legally or financially liable for the death, injury or illness of any animal participating in this study during or after the study period, due to any circumstances whatsoever.

\section{Compensation or Therapy for Accidental Injury or Complications}

The owner of any participating animal will be financially responsible for costs associated with the treatment of complications or accidental injuries associated with this study.

\section{Voluntary Participation and Right to Withdraw}

Participation in this study is voluntary and you have the right to withdraw at any time without penalty. Refusal to participate in, or withdraw from this study will in no way affect the care to which your animal is otherwise entitled.

\section{Primary Contact Person}

To obtain further information regarding this study contact:

Dr Joanne McLean

Bryanston Veterinary Hospital

PO Box 67092, Bryanston, 2021

Tel (011) 7066023

Email: joanne@fuseprop.co.za 


\section{INFORMED OWNER CONSENT}

\section{Study to Determine the Prevalence of and Risk Factors for Feline Hyperthyroidism in South Africa}

I, (full name and ID number), of

(address)

(city, postal code)

Hereby consent to the participation of the following animal in the study cited above. I certify that I am the legal owner (or agent of the owner) of, and am responsible for this animal. I have read, understood and accept the Informed Owner Consent Form.

\section{Animal Details}

Name:

Breed:

Age:

Signature of Owner or Agent:

Date:

Witness:

Date: 


\section{Prevalence of and risk factors for feline hyperthyroidism in South Africa}

\author{
Joanne L McLean ${ }^{1,2}$, Remo G Lobetti ${ }^{2}$, Carmel T Mooney ${ }^{3}$, \\ Peter N Thompson ${ }^{4}$ and Johan P Schoeman ${ }^{1}$
}

Journal of Feline Medicine and Surgery $1-7$

(C) The Author(s) 2016

Reprints and permissions: sagepub.co.uk/journalsPermissions.nav DOI: $10.1177 / 1098612 \times 16684408$ jfms.com

This paper was handled and processed by the European Editorial Office (ISFM) for publication in JFMS

(SAGE

\begin{abstract}
Objectives Hyperthyroidism is a disorder of older cats that may have a geographical variation in prevalence. Prevalence studies have not yet been performed in South Africa, a geographical area where hyperthyroidism in cats has recently been observed and where, reportedly, the incidence appears to be increasing. The purpose of this study was to determine the prevalence of feline hyperthyroidism in South Africa and to identify any potential risk factors. Further information on the worldwide prevalence and possible causative factors would increase our understanding of the aetiology of this disease and help identify any preventive measures.

Methods Serum total thyroxine (tT4) and canine thyroid-stimulating hormone (cTSH) were measured in 302 cats aged 9 years and older that were presented at various veterinary clinics throughout South Africa. In cats with equivocal tT4 and undetectable cTSH values, serum free thyroxine (fT4) was also measured. At the time of blood sampling a questionnaire was completed regarding vaccination history, internal and external parasite control, diet and environment.

Results Prevalence of hyperthyroidism (tT4 $>50 \mathrm{nmol} / \mathrm{l}$ or tT4 between 30 and $50 \mathrm{nmol} / \mathrm{l}$ with TSH $<0.03 \mathrm{ng} / \mathrm{ml}$ and fT4 $>50 \mathrm{pmol} / \mathrm{l})$ was $7 \%$ (95\% confidence interval 4.4-10.4), with no significant difference between healthy (5\%) and sick $(8 \%)$ cats. Cats $\geqslant 12$ years of age (odds ratio $[\mathrm{OR}] 4.3, P=0.02)$ and cats eating canned food (OR 2.1, $P=0.1$ ) were more likely to be diagnosed with hyperthyroidism. No significant relationship between vaccinations, parasite control or indoor environment and hyperthyroidism was observed. Hyperthyroid cats were more likely to present with weight loss (OR 3.2, $P=0.01$ ) and with a heart rate $\geqslant 200$ beats per min (OR $5, P=0.01)$ than cats without the disease.

Conclusions and relevance Hyperthyroidism does not appear to be uncommon in the South African cat population. Risk factors for hyperthyroidism, specifically older age and eating canned food, were present in this as in other reported populations.
\end{abstract}

Accepted: 19 November 2016

\section{Introduction}

Feline hyperthyroidism is a multisystemic disorder arising from excess production of the active thyroid hormones (triiodothyronine and/or thyroxine [T4]) from an abnormally functioning thyroid gland. ${ }^{1}$ Approximately 97-99\% of cases result from benign nodular hyperplasia, adenomatous hyperplasia or adenoma of the thyroid gland. ${ }^{2}$ The disease has been reported in cats between 4 months and 22 years of age with a mean age of 13 years. 3,4 Only $5 \%$ of hyperthyroid cats are younger than 10 years at time of diagnosis. ${ }^{3}$ Clinically and histopathologically, the disease resembles toxic nodular goitre of humans, a disease of the elderly that is more common in iodinedeficient areas. ${ }^{5}$
1Department of Companion Animal Clinical Studies, University of Pretoria, South Africa

²Bryanston Veterinary Hospital, Johannesburg, South Africa ${ }^{3}$ University Veterinary Hospital, University College Dublin, Dublin, Ireland

${ }^{4}$ Department of Production Animal Studies, University of Pretoria, Pretoria, South Africa

\section{Corresponding author:}

Joanne L McLean BSc(Vet Biol), BVSc(Hons), Department of Companion Animal Clinical Studies, University of Pretoria, South Africa and Bryanston Veterinary Hospital, PO Box 67092, Bryanston, 2021, South Africa

Email: joanne@fuseprop.co.za 
Feline hyperthyroidism was first described in 1979 and 1980 in New York and Boston.6,7 Since these initial descriptions, several studies have documented a steady, yet marked increase in the prevalence of the disease in the cat population over time worldwide. 5,8,9 This disorder is now not only recognised as the most common endocrinopathy of the cat, but as one of the more frequently diagnosed disorders in small animal practice within North America, Western Europe, Australia, New Zealand and Japan. ${ }^{1,10,11}$

Several epidemiological studies suggest that hyperthyroidism is more common in countries such as North America, the UK and Germany but less common in countries such as Hong Kong and those in Scandinavia. However, it is difficult to compare directly the results of these studies because of marked differences in inclusion and exclusion criteria. Thus, definitive evidence of true geographical variation is generally lacking. ${ }^{12}$ In one study, the incidence of hyperthyroidism in cats over 9 years of age was compared between veterinary clinics in the UK and in Spain over a 3 year period. ${ }^{13}$ Both had a similar prevalence of cats aged over 9 years of age $(16.4 \%$ and $20.1 \%$, respectively), but there was a significant difference in incidence rates in the UK $(11.9 \%)$ vs those in Spain (1.5\%). The hospital prevalence among cats over 8 years of age in an urban population in Germany was noted as $11.4 \%$ in a 2006 study, ${ }^{14}$ while a Portuguese study in 2014 found a prevalence of $9 \%$ in cats over the age of 10 years. ${ }^{15}$ In Japan, a prevalence of $8.9 \%$ was reported in cats older than 9 years; ${ }^{16}$ in Hong Kong, a prevalence of $3.9 \%$ was found in cats over 10 years of age; ${ }^{17}$ a prevalence of $6 \%$ in apparently healthy cats over 9 years of age was reported in the UK; $;^{18}$ while a more recent UK study reported a prevalence of $8.7 \%$ in cats over 10 years of age presenting to primary-care veterinary practices. ${ }^{17}$ In a 2013 Irish study, a prevalence of $21 \%$ was reported in cats over 10 years of age presenting to private veterinary clinics in the greater Dublin area, ${ }^{19}$ while a 2014 Polish study reported a prevalence of $20.4 \%$ in cats over 7 years of age from Warsaw. ${ }^{20}$

Despite its increasing frequency, the aetiology and underlying pathogenesis of the disorder is not known. Many of the epidemiological studies investigating prevalence have also attempted to identify potential risk factors for feline hyperthyroidism. $5,8,10,21-24$ It has been postulated that immunological, infectious, nutritional (eg, iodine), environmental (eg, toxins or goitrogens) or genetic factors may interact to cause pathological changes within the thyroid gland eventually progressing to hyperthyroidism. Genetic or hereditary factors, nutritional component(s) in cat food leading to metabolic thyroid dysfunction or thyroid-disrupting compounds introduced into the environment or diet are the potential risk factors that have been most closely investigated. ${ }^{11}$ The risk factors identified include living indoors, being female, living in multi-cat households, having dental disease (independent of age), being exposed to topical flea preparations and pesticides, using cat litter (not linked to living indoors), consuming certain flavours of canned foods (fish or liver and giblet flavour) and being a non-purebred cat. However, all of the studies have consistently failed to identify these risk factors and thus their significance remains uncertain. ${ }^{12}$ Nevertheless, a number of these studies have also identified a number of common factors, including increased risk with age, decreased risk in Siamese and Himalayan cats, and increased risk in cats that consume canned cat food, especially pop-top canned food.

As far as we are aware, no prevalence studies have yet been performed in South Africa, a geographical area in which hyperthyroidism in cats has relatively recently been observed and reported and the incidence of which appears, anecdotally, to be on the increase. The purpose of this study was to determine the prevalence of feline hyperthyroidism in South Africa and to identify potential risk factors associated with the disease in this geographical location. Further research into the worldwide prevalence, as well as presence of possible causative factors, would help to elucidate the cause and pathogenesis of this disease and could lead to preventative measures.

\section{Materials and methods}

\section{Case selection}

This analytical cross-sectional study was conducted in cats that were presented for either geriatric check-ups and routine vaccinations or various illnesses at five general veterinary practices throughout South Africa between February 2014 and June 2015. Cats were included in the study if they were 9 years of age or older and had resided solely in South Africa. Cats were excluded from the study if their demeanour precluded the collection of a blood sample, or if they had been treated with drugs that could potentially affect total $\mathrm{T} 4$ (tT4) and thyroid-stimulating hormone (TSH) concentrations such as methimazole, glucocorticoids, phenobarbitone and trimethoprim-potentiated sulfonamides. At the time of blood sampling a questionnaire was completed regarding the health status of the cat, vaccination history, internal and external parasite control, diet and environment. Consent for blood collection was obtained from the owners and ethical approval for the study was also applied for and granted by the animal ethics committee of the University of Pretoria.

\section{Sample collection and analysis}

Blood samples were collected by jugular venepuncture, transferred into plain tubes and couriered on the same day to the Johannesburg or Cape Town branches of IDEXX laboratories, South Africa, where they were centrifuged and the serum separated, aliquoted and stored at $-20^{\circ} \mathrm{C}$. 
On a monthly basis, batches of stored samples were couriered on ice to the clinical pathology laboratory at the Faculty of Veterinary Science, University of Pretoria, to be stored at $-80^{\circ} \mathrm{C}$ for later $\mathrm{tT} 4$ and canine thyroid-stimulating hormone (cTSH) batch analysis. A small batch of samples was also couriered from the University of Pretoria on dry ice to Nationwide Specialist Laboratories, Cambridge, UK, for serum free T4 (fT4) analysis.

Serum tT4 and CTSH concentrations were determined in all cats by use of a chemiluminescent competitive immunoassay (Immulite 1000 Canine Total T4; Siemens Medical Solutions Diagnostics) and a chemiluminescent immunometric assay (Immulite 1000 Canine TSH; Siemens Medical Solutions Diagnostics), respectively. The reference interval (RI) for tT4 was $14-50 \mathrm{nmol} / 1$ $(1.09-3.9 \mu \mathrm{g} / \mathrm{dl}$ ) and for cTSH 0-0.07 ng/ml (historical laboratory RIs). Serum fT4 concentrations were measured in cats with a serum $\mathrm{tT} 4$ concentration between 30 and $50 \mathrm{nmol} / 1$ and a serum cTSH concentration $<0.03$ $\mathrm{ng} / \mathrm{ml}$ using equilibrium dialysis (Antech Diagnostics Inc Free T4 by Equilibrium Dialysis) with an RI of 10-50 $\mathrm{pmol} / 1$ (historical laboratory RIs). All cats with a serum tT4 concentration $>50 \mathrm{nmol} / 1$ or cats with a serum tT4 concentration between 30 and $50 \mathrm{nmol} / 1$, a serum cTSH concentration $<0.03 \mathrm{ng} / \mathrm{ml}$ and a serum fT4 concentration $>50 \mathrm{pmol} / 1$ were classified as hyperthyroid.

\section{Statistical analysis}

The prevalence of hyperthyroidism, with exact binomial $95 \%$ confidence intervals (CIs), was calculated for all cats combined, for cats classified as healthy (no clinically significant disease identified) and for those classified as sick. Prevalence was compared between healthy and sick cats using a two-tailed Fisher's exact test.

Univariate associations between potential risk factors and hyperthyroidism were assessed using a two-tailed Fisher's exact test. Thereafter, all predictors were entered into a multiple logistic regression model to estimate their association with the odds of hyperthyroidism. Nonsignificant variables were eliminated until remaining variables were significant at $P \leqslant 0.1$. The fit of the final logistic regression model was assessed using the Hosmer Lemeshow goodness-of-fit test. Associations between clinical signs and hyperthyroidism were assessed on a univariate level using a two-tailed Fisher's exact test. All analyses were performed using STATA version 14.1. Statistical significance was set as $P \leqslant 0.1$.

\section{Results}

The study population consisted of a total of 302 cats, with the majority of cats being sampled at two private veterinary practices in the Gauteng province of South Africa, namely the Bryanston Veterinary Hospital and Specialist Centre in Johannesburg (220 cats) and the Florida Veterinary Hospital in Krugersdorp (52 cats).
The remaining cats were sampled at private veterinary practices in the Western Cape and Kwa-Zulu Natal provinces of South Africa, namely the Tygerberg Animal Hospital in Cape Town (23 cats), the Hilton Veterinary Hospital (4 cats) and Westville Veterinary Hospital (three cats). Breeds represented included domestic shorthair $(n=201)$, domestic longhair $(n=29)$, Siamese and Siamese Crosses $(n=26)$, Persian and Persian crosses $(n=10)$, Burmese $(n=10)$, Balinese $(n=6)$, Maine Coon and Maine Coon crosses $(n=5)$, domestic medium hair $(\mathrm{n}=4)$, Birman $(\mathrm{n}=2)$, Chinchilla $(\mathrm{n}=2)$, Norwegian Forest $(n=2)$ and one each of Abyssinian, British Blue, Ragdoll, Russian Blue and Somali. There were 161 females and 141 males, of which 265 were neutered. The median age of the cats was 12 years (range 9-24 years).

Of the 302 cats, 118 cats were considered healthy and presented either for annual vaccinations (51 cats) or for routine visits (67 cats), while 184 were presented for various illnesses and considered sick.

The values of the tT4 measurements ranged between 1.3 and $>190 \mathrm{nmol} / 1$ with a mean concentration of 25.8 $\mathrm{nmol} / \mathrm{l}$ and a median concentration of $26.5 \mathrm{nmol} / \mathrm{l}$. Twenty cats had a tT 4 value $>50 \mathrm{nmol} / \mathrm{l}$, while 47 cats had a tT4 value between 30 and $50 \mathrm{nml} / 1$. Of the 47 cats with a tT4 value between 30 and $50 \mathrm{nmol} / \mathrm{l}, 21 \mathrm{had}$ a cTSH value $<0.03 \mathrm{ng} / \mathrm{ml}$, of which only one cat had a fT4 value $>50 \mathrm{pmol} / \mathrm{l}$. Only one of the cats with a tT4 value $>50 \mathrm{nmol} / 1 \mathrm{had}$ a cTSH value $>0.03 \mathrm{ng} / \mathrm{ml}$. In total 21 cats were diagnosed as being hyperthyroid. Of the 21 hyperthyroid cats, $95 \%$ had an undetectable cTSH.

The prevalence of hyperthyroidism within the study population was 7\% (95\% CI 4.4-10.0) with no significant difference in prevalence between healthy $(5 \%$ [95\% CI $1.9-11.0])$ and sick (8\% [95\% CI 4.6-13.0]) cats. There were no statistically significant differences in prevalence of hyperthyroidism between male and female cats, between purebred vs non-purebred cats or between Siamese and non-Siamese cats (Table 1). No statistically significant relationships between vaccinations, parasite control or indoor environment and hyperthyroidism were observed.

Only age and the presence of canned food in the diet were retained in the final logistic regression model of risk factors (Table 2). Cats $\geqslant 12$ years of age (odds ratio [OR] 4.3 [95\% CI 1.2-15.0]; $P=0.02)$ and cats with canned food in their diet (OR 2.1 [95\% CI 0.8-5.4]; $P=0.1$ ) were more likely to be diagnosed with hyperthyroidism.

Table 3 lists the frequency of the main clinical features in the hyperthyroid cats. Weight loss and vomiting were the most common findings, followed by tachypnoea, tachycardia, presence of a cardiac murmur and polyphagia. Clinical features typically associated with hyperthyroidism were only noted in 14/21 hyperthyroid cats and only two had a palpable goitre. The mean $\mathrm{tT} 4$ concentration in the group of hyperthyroid cats with clinical signs 
Table 1 Univariate analysis of risk factors for hyperthyroidism (total thyroxine [tT4] $>50 \mathrm{nmol} / \mathrm{l}$ or tT4 between 30 and 50 $\mathrm{nmol} / \mathrm{l}$ with thyroid-stimulating hormone $<0.03 \mathrm{ng} / \mathrm{ml}$ and free $\mathrm{T} 4>50 \mathrm{pmol} / \mathrm{l})$

\begin{tabular}{|c|c|c|c|c|c|}
\hline \multirow[b]{2}{*}{ Variable } & \multirow[b]{2}{*}{ Category } & \multirow[b]{2}{*}{$N$} & \multicolumn{3}{|c|}{ Hyperthyroid cats } \\
\hline & & & $\mathrm{n}$ & $\%$ & $P$ value* \\
\hline \multirow[t]{3}{*}{ Age (years) } & $9-11$ & 121 & 3 & 3 & 0.03 \\
\hline & $12-14$ & 93 & 10 & 11 & \\
\hline & $>14$ & 88 & 8 & 9 & \\
\hline \multirow[t]{2}{*}{ Sex } & Female & 161 & 13 & 8 & 0.50 \\
\hline & Male & 141 & 8 & 6 & \\
\hline \multirow[t]{11}{*}{ Breed } & DSH & 201 & 13 & 7 & 0.62 \\
\hline & DLH & 29 & 4 & 14 & \\
\hline & Siamese/Siamese crosses & 26 & 1 & 4 & \\
\hline & Persian/Persian crosses & 10 & 0 & 0 & \\
\hline & Burmese & 10 & 0 & 0 & \\
\hline & Balinese & 6 & 1 & 17 & \\
\hline & Other breeds & 20 & 2 & 10 & \\
\hline & Purebred & 61 & 3 & 5 & 0.57 \\
\hline & Non-purebred & 241 & 18 & 8 & \\
\hline & Siamese/Siamese crosses & 26 & 1 & 4 & 1.00 \\
\hline & Other breeds & 276 & 21 & 8 & \\
\hline \multirow{3}{*}{$\begin{array}{l}\text { Number of cats } \\
\text { in household }\end{array}$} & 1 & 94 & 8 & 9 & 0.78 \\
\hline & 2 & 104 & 7 & 7 & \\
\hline & $>2$ & 104 & 6 & 6 & \\
\hline \multirow[t]{3}{*}{ Vaccinated } & Yes & 270 & 20 & 7 & 0.72 \\
\hline & No & 18 & 0 & 0 & \\
\hline & Not sure & 14 & 1 & 7 & \\
\hline \multirow[t]{3}{*}{ Dewormed } & Yes & 274 & 20 & 7 & 0.44 \\
\hline & No & 18 & 0 & 0 & \\
\hline & Not sure & 10 & 1 & 10 & \\
\hline \multirow[t]{3}{*}{ Flea control } & Yes & 139 & 8 & 6 & 0.54 \\
\hline & No & 162 & 13 & 8 & \\
\hline & Not sure & 1 & 0 & 0 & \\
\hline \multirow[t]{2}{*}{ Exclusively indoors } & Yes & 246 & 18 & 7 & 0.78 \\
\hline & No & 56 & 3 & 5 & \\
\hline \multirow[t]{2}{*}{ Canned food in diet } & Yes & 71 & 8 & 11 & 0.11 \\
\hline & No & 231 & 13 & 6 & \\
\hline \multirow[t]{2}{*}{ Hunter } & Yes & 120 & 8 & 7 & 1 \\
\hline & No & 182 & 13 & 7 & \\
\hline \multirow[t]{3}{*}{ Water } & Tap (unboiled) & 256 & 18 & 7 & 0.34 \\
\hline & Tap (boiled) & 32 & 1 & 3 & \\
\hline & Mineral & 14 & 2 & 14 & \\
\hline
\end{tabular}

${ }^{*} P$ value for two-tailed Fisher's exact test

$\mathrm{DSH}=$ domestic shorthair; $\mathrm{DLH}=$ domestic longhair

was $114 \mathrm{nmol} / 1$ (range 56-193 nmol/l), while in the group of hyperthyroid cats without clinical signs this value was $79 \mathrm{nmol} / \mathrm{l}$ (range 40.3-193 nmol/l). Univariable analysis for these clinical signs as predictors of hyperthyroidism demonstrated that hyperthyroid cats were more likely to present with weight loss (OR 3.2 [95\% CI 1.2-8.9]; $P=0.01$ ) and with a heart rate $\geqslant 200$ beats per min (bpm; OR 5 [95\% CI 1.7-16.1]; $P=0.01$ ) than cats without the disease (Table 4).

\section{Discussion}

This study showed that the prevalence of hyperthyroidism in older cats presenting to private veterinary clinics in South Africa was 7\%. This is similar to the prevalence rates reported in older cat populations in Japan and Portugal, 15,16 higher than that reported in Hong Kong but less than that reported in the UK and Germany. ${ }^{14,17}$ It is, however, difficult to make direct comparisons between the results of different prevalence studies 
Table 2 Final logistic regression model of risk factors for hyperthyroidism (total thyroxine [tT4] $>50 \mathrm{nmol} / \mathrm{l}$ or tT4 between 30 and $50 \mathrm{nmol} / \mathrm{l}$ with thyroid-stimulating hormone $<0.03 \mathrm{ng} / \mathrm{ml}$ and free T4 $>50 \mathrm{pmol} / \mathrm{l}$ )

$\begin{array}{lllll}\text { Variable } & \text { Category } & \text { OR } & 95 \% \mathrm{Cl} & P \text { value } \\ \text { Age (years) } & <12^{*} & 1.00 & - & - \\ & >12 & 4.31 & 1.24-15.12 & 0.02 \\ \text { Canned food } & \mathrm{No}^{*} & 1.00 & - & - \\ \text { in diet } & \text { Yes } & 2.10 & 0.82-5.36 & 0.1\end{array}$

*Reference category

$\mathrm{OR}=$ odds ratio; $\mathrm{Cl}=$ confidence interval
Table 3 Presenting clinical features in 21 hyperthyroid cats

$\begin{array}{lc}\text { Finding } & \text { Number of cats } \\ \text { Weight loss } & 12 \\ \text { Vomiting } & 7 \\ \text { Tachypnoea } & 4 \\ \text { Tachycardia }(\geqslant 240 \mathrm{bpm}) & 3 \\ \text { Polyphagia } & 3 \\ \text { Cardiac murmur } & 3 \\ \text { Diarrhoea } & 2 \\ \text { Palpable thyroid lobe } & 2\end{array}$

$\mathrm{bpm}=$ beats per minute

Table 4 Univariate analysis of clinical signs associated with hyperthyroidism (total thyroxine [tT4] $>50 \mathrm{nmol} / \mathrm{l}$ or tT4 between 30 and $50 \mathrm{nmol} / \mathrm{l}$ with thyroid-stimulating hormone $<0.03 \mathrm{ng} / \mathrm{ml}$ and free T4 $>50 \mathrm{pmol} / \mathrm{l}$ )

\begin{tabular}{|c|c|c|c|c|c|}
\hline \multirow[b]{2}{*}{ Variable } & \multirow[b]{2}{*}{ Category } & \multirow[b]{2}{*}{$\mathrm{N}$} & \multicolumn{3}{|c|}{ Hyperthyroid cats } \\
\hline & & & $n$ & $\%$ & $P$ value* \\
\hline \multirow[t]{2}{*}{ Weight loss } & Yes & 95 & 12 & 13 & 0.013 \\
\hline & No & 207 & 9 & 4 & \\
\hline \multirow[t]{2}{*}{ Polyphagia } & Yes & 46 & 3 & 7 & 1.00 \\
\hline & No & 256 & 18 & 7 & \\
\hline \multirow[t]{3}{*}{ Heart rate (bpm) } & $<200$ & 193 & 6 & 3 & 0.001 \\
\hline & $200-240$ & 99 & 12 & 12 & \\
\hline & $>240$ & 10 & 3 & 30 & \\
\hline \multirow[t]{2}{*}{ Cardiac murmur } & Yes & 16 & 3 & 19 & 0.090 \\
\hline & No & 286 & 18 & 6 & \\
\hline \multirow[t]{3}{*}{ Respiratory rate and pattern } & Normal & 277 & 17 & 6 & 0.042 \\
\hline & Increased & 23 & 3 & 13 & \\
\hline & Dyspnoeic & 2 & 1 & 50 & \\
\hline \multirow[t]{2}{*}{ Vomiting } & Yes & 75 & 7 & 9 & 0.431 \\
\hline & No & 227 & 14 & 6 & \\
\hline \multirow[t]{2}{*}{ Diarrhoea } & Yes & 12 & 2 & 17 & 0.199 \\
\hline & No & 290 & 19 & 7 & \\
\hline
\end{tabular}

${ }^{*} P$ value for two-tailed Fisher's exact test

$\mathrm{bpm}=$ beats per minute

because of the different inclusion and exclusion criteria and study methods used. This result does, however, support some geographical variation in the prevalence of the disease worldwide and that this variation could reflect differences in dietary, environmental and/or genetic factors. What is interesting to note is that the disease in the South African cat population appears to be much more prevalent than anecdotally thought. This may be owing to lack of awareness of the disease in clinical practice or lack of recognition of clinical signs by South African veterinarians.

Unlike previous prevalence studies, in this study serum tT4 and cTSH was tested in all cats and fT4 tested in cats that had a serum tT4 between 30 and $50 \mathrm{nmol} / 1$ and a cTSH $<0.03 \mathrm{ng} / \mathrm{ml}$ in an attempt to detect hyperthyroid cats with early or subclinical disease or hyperthyroid cats with severe concurrent non-thyroidal illness. The cTSH assay has been used in the diagnosis of feline hyperthyroidism with an RI of $0.03-0.15 \mathrm{ng} / \mathrm{ml}$ for older cats. ${ }^{25}$ In patients with subclinical and occult hyperthyroidism, cTSH levels are often low or undetectable. ${ }^{26}$ One study that evaluated the usefulness of cTSH as a diagnostic test for feline hyperthyroidism, using thyroid scintigraphy as the gold standard, concluded that measurement of serum cTSH concentration was a very sensitive, but non-specific, diagnostic test with approximately $98 \%$ of hyperthyroid cats having serum cTSH concentrations suppressed below the limit of quantification $(<0.03$ $\mathrm{ng} / \mathrm{ml}) .{ }^{27}$ Unfortunately, the current commercial cTSH assay cannot accurately measure concentrations low 
enough to distinguish clearly between euthyroid cats and hyperthyroid cats with suppressed concentrations. Combining serum cTSH with T4 or fT4 concentrations lowered the test sensitivity of cTSH from $98 \%$ to $97 \%$ but markedly increased overall test specificity (from 69.9\% to $98.8 \%$ ). Interestingly, in our study $95 \%$ of the hyperthyroid cats had an undetectable cTSH.

There was no difference in this study in the prevalence of hyperthyroidism between cats that were considered healthy and those that were considered sick. This may suggest that the disease is currently under-diagnosed in South Africa and that its early manifestations are insidious and challenging to recognise because it is often confused with other diseases or normal ageing changes.

In this current study there was an increased risk of hyperthyroidism with increasing age, with cats older than 12 years of age being four times more likely to have the disease. This is consistent with previous studies, ${ }^{10,17,24}$ and also is in agreement with the fact that feline hyperthyroidism is a disease of middle-aged-to-old cats. In this current study, there were more female $(\mathrm{n}=13[62 \%])$ than male ( $\mathrm{n}=8$ [38\%]) cats with hyperthyroidism, but the difference was not statistically significant. Most previously published studies report no sex predilection for feline hyperthyroidism. 7,8,22,28 However, two separate studies reported a significantly higher prevalence of hyperthyroidism in female cats, 5,10 and significantly more affected male than female cats. ${ }^{14}$

Two previous epidemiological studies have shown that Siamese cats have a significantly lower risk of developing hyperthyroidism compared with other breeds,, 822 and three studies have demonstrated a protective effect in purebred cats. ${ }^{10,21,24}$ In our study there were more nonpurebred cats $(n=18[86 \%])$ with hyperthyroidism than purebred cats ( $\mathrm{n}=3[14 \%])$, as well as a lower proportion of Siamese and Siamese-cross cats with hyperthyroidism $(n=1[5 \%])$, than all other breeds $(n=20[95 \%])$. However, the differences were, again, not statistically significant.

The present study and four previous studies all identified an increased risk of hyperthyroidism associated with an increased proportion of canned cat food in the diet. $5,8,22,23$ One study incriminated particular flavours of canned food (fish, liver and giblets), ${ }^{23}$ and another incriminated cans with plastic linings and easy-open (pop-top) lids. ${ }^{5}$ Biologically plausible explanations for an association between feeding canned foods, especially of certain flavours, and hyperthyroidism may relate to the iodine content of canned vs dry cat foods (although the role that iodine plays in development of the disease is still largely unknown), ${ }^{29,30}$ or the presence in the canned food of thyroid disruptors such as bisphenol A, polybrominated diphenyl ethers or flavonoids. ${ }^{31}$ However, all these nutritional causes and risk factors remain speculative and lifelong prospective longitudinal studies are needed to investigate properly the role nutritional risk factors have in the development of hyperthyroidism. ${ }^{31}$

In this study, clinical features typically associated with hyperthyroidism were only noted in 14/21 hyperthyroid cats and only two had a palpable goitre. Thus, 7/21 hyperthyroid cats showed no overt clinical signs, which could be ascribed to the presence of a mild or early form of the disease (mean tT4 concentration of 114 $\mathrm{nmol} / \mathrm{l}$ in group of cats with clinical signs vs $79 \mathrm{nmol} / 1$ in group of cats without clinical signs), but could also be due to lack of awareness of the disease by practitioners in South Africa owing to their preconceived impression that the disease is not prevalent in the country. The lack of a palpable thyroid nodule in 19/21 hyperthyroid cats was unexpected and could either be due to inexperience of the veterinarians or lack of thyroid enlargement owing to an early or subclinical form of the disease. Despite the absence of recognisable clinical signs in some of the hyperthyroid cats, this study showed that hyperthyroidism should be considered in any older cat demonstrating weight loss or a heart rate $\geqslant 200 \mathrm{bpm}$.

The present study had some limitations that need to be considered. The low prevalence of hyperthyroidism, combined with the limited sample size, made it difficult to compare the group of hyperthyroid cats with the nonhyperthyroid cats. Bias may have been present as the study only included cats that were brought to veterinary practices. Although this bias may have influenced the risk factors identified in the study, it most likely had very little bearing on the prevalence of the disease reported as the veterinarian is only interested in the probability of encountering the disease in private practice.

\section{Conclusions}

Feline hyperthyroidism appears to be a relatively common disease in older cats presenting to private veterinary clinics in South Africa. Hyperthyroidism needs to be considered in any older individual demonstrating weight loss or a heart rate $\geqslant 200 \mathrm{bpm}$ in this cat population. The risk factors for development of feline hyperthyroidism identified in South Africa's relatively isolated population of cats appear to be somewhat similar to those that have been identified elsewhere.

Acknowledgements This study would not have been possible without the cooperation of all the veterinarians and cat owners in the various parts of South Africa, to whom the authors are greatly indebted. Our gratitude is also extended to all the staff at IDEXX Laboratories, South Africa, who not only took care of preparing and freezing the samples, but also provided valuable support in transportation of the samples to the various laboratories.

Conflicts of interest The authors declared no potential conflicts of interest with respect to the research, authorship, and/ or publication of this article. 
Funding Financial support was provided by the Waltham Foundation, Waltham Centre for Pet Nutrition, Waltham-onthe-Wolds, UK.

\section{References}

1 Mooney CT. Hyperthyroidism. In: Ettinger S and Feldman $\mathrm{E}$ (eds). Textbook of veterinary internal medicine: diseases of the dog and cat. 7th ed. Philiadelphia, PA: WB Saunders, 2010, pp 1761-1779.

2 Gunn-Moore D. Feline endocrinopathies. Vet Clin North Am Small Anim Pract 2005; 35: 171-210.

3 Peterson ME, Randolf JF and Mooney CT. Endocrine disease. In: Sherding RD (ed). The cat: diseases and clinical management. New York: Churchill Livingston, 1994, pp 1416-1452.

4 Gordan JM, Ehrhart E J, Sisson DD, et al. Juvenile hyperthyroidism in a cat. J Am Anim Hosp Assoc 2003; 39: 67-71.

5 Edinboro $\mathrm{CH}$, Scott-Moncrieff JC, Janovitz E, et al. Epidemiologic study of relationships between consumption of commercial canned food and risk of hyperthyroidism in cats. J Am Vet Med Assoc 2004; 224: 879-886.

6 Holzworth J, Theran P and Carpenter JL. Hyperthyroidism in the cat: ten cases. J Am Vet Med Assoc 1980; 176: 345-353.

7 Peterson ME, Kintzer PP, Cavanagh PG, et al. Feline hyperthyroidism: pretreatment clinical and laboratory evaluation of 131 cases. J Am Vet Med Assoc 1981; 183: 103-110.

8 Scarlett JM, Moise NS and Ray IJ. Feline hyperthyroidism: a descriptive and case control study. Prev Vet Med 1998; 6: 295-309.

9 Kraft W and Buchler F. Hyperthyroidism: incidence in the cat. Tierarztl Prax Ausg Klientiere Heimtiere 1999; 27: 386-388.

10 Olczak J, Jones BR, Pfeiffer DU, et al. Multivariate analysis of risk factors for feline hyperthyroidism in New Zealand. N Z Vet J 2005; 53: 53-58.

11 Peterson ME and Ward CR. Etiopathologic findings of hyperthyroidism in cats. Vet Clin North Am Small Anim Pract 2007; 37: 633-645.

12 Sparkes A. Where are we now? Historical and epidemiological aspects of feline hyperthyroidism. Proceedings of the Global Symposium on Feline Hyperthyroidism: The Rise and Fall of Thyroxine; 2012 May 9-11; Barcelona, Spain. pp 5-8.

13 Wakeling J, Melian C and Font A. Evidence for differing incidences of feline hyperthyroidism in London, UK and Spain. Proceedings of the 15th ECVIM-CA Congress; 2005 September 1-3; Glasgow, UK. p 220.

14 Sassnau R. Epidemiological investigation on the prevalence of feline hyperthyroidism in an urban population in Germany. Tierarztliche Praxis Kleintiere 2006; 34: 450-457.

15 Horspool LJI and Dias Neves R. Prevalence of hyperthyroidism in portugese cats. Proceedings of the 24th
ECVIM-CA Congress; 2014 September 4-6; Mainz, Germany. p 198.

16 Miyamoto Y, Miyata I and Kurobane K. Prevalence of feline hyperthyroidism in Osaka and the Chugoku region. Jpn Vet Med Assoc 2002; 55: 289-292.

17 Stephens MJ, O'Neill DG, Church DB, et al. Feline hyperthyroidism reported in primary-care veterinary practices in England: prevalence, associated factors and spatial distribution. Vet Rec 2014; 175: 458-462.

18 Wakeling J, Elliott J and Syme H. Evaluation of predictors for the diagnosis of hyperthyroidism in cats. J Vet Inten Med 2011; 25: 1057-1065.

19 Gallagher B and Mooney CT. Prevalence and risk factors for hyperthyroidism in Irish cats from the greater Dublin area. J Vet Intern Med 2013; 27: 689.

20 Gojska-Zygner O, Lechowski R and Zygner W. Prevalence of feline hyperthyroidism in mature cats in urban population in Warsaw. Bull Vet Inst Pulawy 2014; 58: 267-271.

21 De Wet CS, Thomson PN, Mooney CT, et al. Prevalence of and risk factors for feline hyperthyroidism in Hong Kong. J Feline Med Surg 2009; 11: 315-321.

22 Kass PH, Peterson ME, Levy JK, et al. Evaluation of environmental, nutritional and host factors in cats with hyperthyroidism. J Vet Intern Med 1999; 13: 323-329.

23 Martin KM, Rossing MA, Ryland LM, et al. Evaluation of dietary and environmental risk factors for hyperthyroidism in cats. J Am Vet Med Assoc 2000; 217: 853-856.

24 Wakeling J, Everard A, Brodbel D, et al. Risk factors for feline hyperthyroidism in the UK. J Small Anim Pract 2009; 50: 406-414.

25 Wakeling JM, Moore K, Elliott J, et al. Diagnosis of hyperthyroidism in cats with mild chronic kidney disease. J Small Anim Pract 2008; 49: 287-294.

26 Wakeling J, Smith K, Scase T, et al. Subclinical hyperthyroidism in cats: a spontaneous model of subclinical toxic nodular goiter in humans? Thyroid 2007; 17: 1201-1209.

27 Peterson ME, Guterl JN, Nichols R, et al. Evaluation of serum thyroid-stimulating hormone concentration as a diagnostic test for hyperthyroidism in cats. J Vet Intern Med 2015; 29: 1327-1334.

28 Broussard JD, Peterson ME and Fox PR. Changes in clinical and laboratory findings in cats with hyperthyroidism from 1983 to 1993. J Am Vet Med Assoc 1995; 206: 302-305.

29 Johnson LA, Ford HC, Tarttelin MF, et al. Iodine content of commercially-prepared cat foods. N Z Vet J 1992; 40: 18-20.

30 Tarttelin MF, Johnson LA, Cooke RR, et al. Serum free thyroxine levels respond inversely to changes in levels of dietary iodine in the domestic cat. N Z Vet J 1992; 40: 66-68.

31 Van Hoek I, Hesta M and Biourge V. A critical review of food-associated factors proposed in the etiology of feline hyperthyroidism. J Feline Med Surg 2015; 17: 837-847. 